\title{
${ }^{\ominus}$ Assessment of Extreme Precipitation Indices over Indochina and South China in CMIP6 Models $\mathscr{A}$
}

\author{
Bin TANG, ${ }^{\mathrm{a}, \mathrm{b}}$ Wenting Hu, ${ }^{\mathrm{a}, \mathrm{b}}$ AND ANMIN DUAN ${ }^{\mathrm{a}, \mathrm{b}}$ \\ ${ }^{\text {a }}$ State Key Laboratory of Numerical Modeling for Atmospheric Sciences and Geophysical Fluid Dynamics, Institute of Atmospheric \\ Physics, Chinese Academy of Sciences, Beijing, China \\ ${ }^{\mathrm{b}}$ University of Chinese Academy of Sciences, Beijing, China
}

(Manuscript received 9 December 2020, in final form 20 May 2021)

\begin{abstract}
Precipitation extremes over the Indochina and South China (INCSC) region simulated by 40 global climate models from phase 6 of the Coupled Model Intercomparison Project (CMIP6) were quantitatively assessed based on the skill score metrics of four extreme precipitation indices when compared with observational results from a high-resolution daily precipitation dataset for 1958-2014. The results show that it is difficult for most of the CMIP6 models to reproduce the observed spatial pattern of extreme precipitation indices in the INCSC region. The interannual variability of the extreme precipitation indices is relatively better simulated for South China than for Indochina. In general, most of the CMIP6 models perform better in South China compared with Indochina when taking both the simulations of spatial pattern and interannual variability into consideration. Only three models (EC-EARTH3, EC-EARTH3-Veg, and NorESM2-MM) can successfully reproduce both the spatial pattern and the interannual variability for the INCSC region. Through model ranking, the multimodel ensemble generated by a selection of the most skillful models leads to a more realistic simulation of the extreme precipitation indices both in South China and Indochina. Better simulation of the meridional wind component over South China and the water vapor convergence over Indochina can partly reduce the wet biases, resulting in a more realistic simulation of extreme precipitation indices over the INCSC region.
\end{abstract}

KEYWORDS: Extreme events; Model comparison; Model evaluation/performance

\section{Introduction}

Evidence has shown that the global climate has undergone a significant change characterized by warming over the past century (IPCC 2007, 2013). Against the background of global warming, the acceleration of the hydrological cycle and the adjustment of the general circulation have led to a clear increase in extreme precipitation events. The climate dynamics in the Indochina and South China (INCSC) region are extremely complex, as the region is influenced by three regional monsoon systems (the Indian summer monsoon, East Asian summer monsoon, and the western North Pacific summer monsoon) (Chen and Yoon 2000; Yang et al. 2020). In addition, the distinctive topography and complex air-sea interactions make the spatiotemporal variation of precipitation and extreme precipitation in the INCSC region more complicated than in other regions (Buckley et al. 2014; Räsänen et al. 2016; Ge et al. 2017). Since extreme precipitation events severely impact economic activity and human lives in the INCSC region, comprehending and quantifying extreme precipitation in the region is of vital importance for implementing proactive measures to reduce the risks from extreme precipitation

๑ Denotes content that is immediately available upon publication as open access.

Supplemental information related to this paper is available at the Journals Online website: https://doi.org/10.1175/JCLI-D-200948.s1.

Corresponding author: Wenting Hu, hwt@lasg.iap.ac.cn
(Asian Development Bank 2009; Krishnan et al. 2015; Pai and Sridhar 2015; Kim et al. 2018).

Global climate models are widely used to simulate the dynamics and state of the present-day climate before the projection of future climate (Orlowsky and Seneviratne 2012; Samuels et al. 2017; Wang et al. 2017; Rao et al. 2019). However, even the most advanced models still have difficulties in capturing the basic features of extreme precipitation because of the complex variability in the temporal and spatial scales involved (Kim et al. 2018). Sillmann et al. (2013) conducted a comprehensive global analysis of the ability of phase 5 of the Coupled Model Intercomparison Project (CMIP5) models to simulate climate extremes indices, finding that the models tend to overestimate extreme precipitation and underestimate the number of consecutive wet days. In phase 3 of CMIP (CMIP3) and CMIP5 models, the uncertainties in simulating extreme precipitation in the tropics and subtropics remain very large (Toreti et al. 2013; Kharin et al. 2013). Based on comparisons with satellite data, previous studies have shown that most CMIP3 models underestimate the response of extreme precipitation intensity to temperature across the globe, especially in the tropics (Allan et al. 2010; O'Gorman 2012). Using a 10-member subset of the CMIP5 models, Raghavan et al. (2017) showed that most of the models are unable to reproduce the historical climate of Southeast Asia. Li et al. (2019) comprehensively evaluated the accuracies of 31 CMIP5 models in simulating the spatiotemporal

This article is licensed under a Creative Commons Attribution 4.0 license (http://creativecommons.org/ licenses/by/4.0/).

DOI: 10.1175/JCLI-D-20-0948.1 
characteristics of precipitation. The results showed that nearly all the models overestimate the annual mean precipitation in Southeast Asia. As for China, although the CMIP5 models can successfully capture the basic characteristics of the spatial variation and interannual variability of extreme precipitation in eastern China, they still have a wet bias in North China and a dry bias in South China (Ou et al. 2013; Jiang et al. 2015; Sun et al. 2015; Rao et al. 2019).

Recently, results from the state-of-the-art global climate models involved in phase 6 of CMIP (CMIP6) have started to become available. Most of the CMIP6 models have higher resolutions and improved parameterization schemes for cloud microphysical processes and biogeochemical processes of the climate system compared with CMIP5 models (Eyring et al. 2016; Eyring et al. 2019), and therefore better simulation skill in reproducing the historical climate is expected in the CMIP6 models. Compared with other regions such as North America and Europe, as yet there have been relatively few studies that have focused on model evaluation and associated bias analyses of extreme precipitation in the INCSC region (Misra and DiNapoli 2013; Nguyen-Le et al. 2015; Tangang et al. 2020). Also, quantitative analysis of extreme precipitation in the INCSC region is lacking in previous studies (Raghavan et al. 2017). Therefore, it is important to quantify how well each CMIP6 model simulates the spatial pattern and temporal variability of extreme precipitation in the INCSC region, and to determine which CMIP6 models can be regarded as the most skillful models in simulating the extreme precipitation indices over the INCSC region, based on a set of model performance metrics. To achieve this, we need to establish quantitative indicators to intuitively reflect the capacity of each model to reproduce the observed features of precipitation and extreme precipitation in the INCSC region. Then, based on these quantitative analyses, a further comparison between ensembles of skillful and less skillful models will provide some suggestions for improving the simulation of precipitation and extreme precipitation in the INCSC region.

The mechanisms behind, and characteristics of, precipitation and extreme precipitation over South China and Indochina are different (Kanae et al. 2001; Chi et al. 2005; Buckley et al. 2014). Therefore, an evaluation of the ability of these models to simulate extreme precipitation indices should be conducted separately for South China and Indochina, which will provide a better reference for model selection. As using annual extreme precipitation indices is conventional and widely accepted (e.g., Alexander and Arblaster 2017; Zhu et al. 2020; Ge et al. 2021), the main goal of this study is to quantitatively evaluate the ability of CMIP6 models to simulate the spatial pattern and temporal variation of present-day precipitation and extreme precipitation over South China and Indochina using different skill score metrics on annual basis. Then, the most skillful and less skillful models in the two subregions will be classified to different model ensembles in view of the overall rankings among models. Finally, we discuss the possible causes of the biases derived from the comparison between the two model ensembles and the observations.

The remainder of the paper is organized as follows: Section 2 describes the data and methods. The CMIP6 model simulations

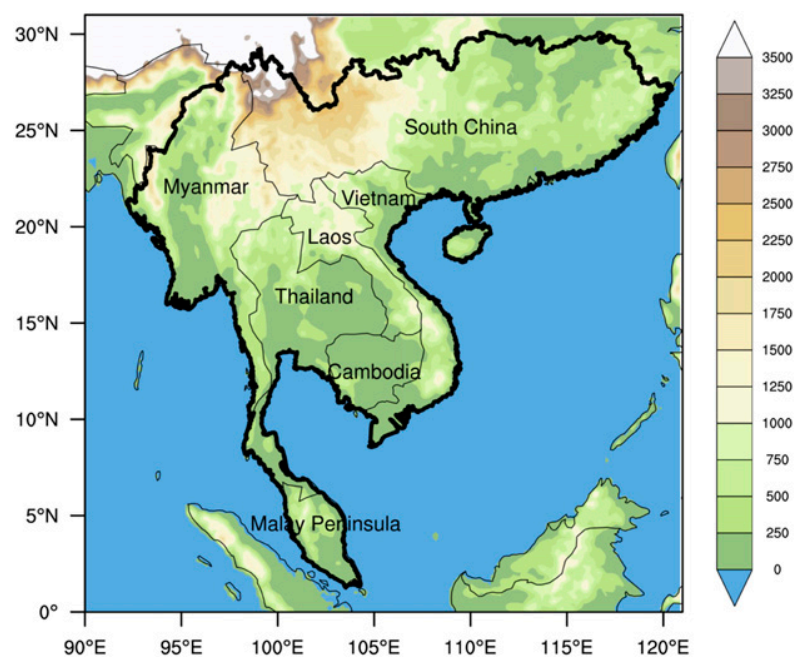

FIG. 1. Map showing the location and altitudes (shading; $\mathrm{m}$ ) of the INCSC region.

of precipitation extremes over the INCSC region are presented in section 3. The performance of selected models and the possible causes of model biases are investigated in section 4 . Finally, section 5 provides a summary and discussion.

\section{Data and methods}

\section{a. Description of the INCSC region}

Located in the tropical monsoon region $\left(0^{\circ}-30^{\circ} \mathrm{N}, 90^{\circ}-\right.$ $\left.120^{\circ} \mathrm{E}\right)$, the INCSC region includes South China, Myanmar, Thailand, Laos, Vietnam, Cambodia, and the Malay Peninsula (Fig. 1). In terms of its geographical location, the INCSC region is a key area connecting the Bay of Bengal and the South China Sea. The climate of the INCSC region is not only related to the formation of the Asian monsoon and associated changes, but also influences the retreat of the western Pacific subtropical high in the Northern Hemisphere (Li et al. 2019). Therefore, it is of vital importance to evaluate how well each CMIP6 model captures the climatic characteristics of the observed data, so that climate change research related to the INCSC region can be better conducted.

\section{b. Data}

Daily precipitation data from 40 CMIP6 models for the period 1958-2014 were used for the calculation of extreme precipitation indices over the INCSC region. Basic information for each model, including the institution ID, modeling center and country, model name, and atmospheric resolution, is listed in Table 1. Further details can be obtained online (https://www.wcrp-climate.org/wgcm-cmip). Only one realization (usually r1i1p1f1, except r2i1p1f1 for CAMS-CSM1.0; r1i1p1f2 for CNRM-CM6.1-HR, CNRM-CM6.1, CNRMESM2.1, MIROC-ES2L, and UKESM1.0-LL; and r1i1p1f3 for HadGEM3-GC31-LL and HadGEM3-GC31-MM) of the historical experiment by each model was used in this study in order to have as many models as possible. Compared with station observations, gridded datasets with homogenization 
TABLE 1. The model institution ID, modeling center and country, model name, and atmospheric resolution of the 40 CMIP6 global climate models used in this study.

\begin{tabular}{|c|c|c|c|}
\hline Institution ID & Modeling center and country & Model name & $\begin{array}{l}\text { Atmospheric } \\
\text { resolution } \\
(\text { lat } \times \text { lon })\end{array}$ \\
\hline CSIRO-ARCCSS & $\begin{array}{l}\text { Commonwealth Scientific and Industrial Research } \\
\text { Organization, Australian Research Council Centre of } \\
\text { Excellence for Climate System Science, Australia }\end{array}$ & ACCESS-CM2 & $1.25^{\circ} \times 1.875^{\circ}$ \\
\hline CSIRO & $\begin{array}{l}\text { Commonwealth Scientific and Industrial Research } \\
\text { Organization, Australia }\end{array}$ & ACCESS-ESM1.5 & $1.25^{\circ} \times 1.875^{\circ}$ \\
\hline AWI & Alfred Wegener Institute, Germany & AWI-ESM-1.1-LR & $1.875^{\circ} \times 1.875^{\circ}$ \\
\hline \multirow[t]{2}{*}{$\mathrm{BCC}$} & Beijing Climate Center, China & BCC_CSM2-MR & $1.125^{\circ} \times 1.225^{\circ}$ \\
\hline & & BCC-ESM1 & $1.406^{\circ} \times 1.406^{\circ}$ \\
\hline CAMS & Chinese Academy of Meteorological Sciences, China & CAMS-CSM1.0 & $1.125^{\circ} \times 1.125^{\circ}$ \\
\hline $\mathrm{CCCma}$ & $\begin{array}{l}\text { Canadian Centre for Climate Modeling and Analysis, } \\
\text { Environment and Climate Change Canada, Canada }\end{array}$ & CanESM5 & $1.406^{\circ} \times 1.406^{\circ}$ \\
\hline \multirow[t]{3}{*}{ NCAR } & $\begin{array}{l}\text { National Center for Atmospheric Research, Climate and Global } \\
\text { Dynamics Laboratory, United States }\end{array}$ & CESM2(WACCM) & $0.938^{\circ} \times 1.25^{\circ}$ \\
\hline & & CESM2 & $0.938^{\circ} \times 1.25^{\circ}$ \\
\hline & & CESM2-FV2 & $1.875^{\circ} \times 2.5^{\circ}$ \\
\hline $\mathrm{CMCC}$ & $\begin{array}{l}\text { Fondazione Centro Euro-Mediterraneo sui Cambiamenti } \\
\text { Climatici, Italy }\end{array}$ & CMCC-CM2-SR5 & $0.938^{\circ} \times 1.25^{\circ}$ \\
\hline \multirow[t]{3}{*}{ CNRM-CERFACS } & $\begin{array}{l}\text { Centre National de Recherches Meteorologiques, Centre } \\
\text { Europeen de Recherche et de Formation Avancee en Calcul } \\
\text { Scientifique, France }\end{array}$ & CNRM-CM6.1 & $1.406^{\circ} \times 1.406^{\circ}$ \\
\hline & & CNRM-ESM2.1 & $1.406^{\circ} \times 1.406^{\circ}$ \\
\hline & & CNRM-CM6.1-HR & $0.5^{\circ} \times 0.5^{\circ}$ \\
\hline \multirow{3}{*}{$\begin{array}{l}\text { EC-EARTH- } \\
\text { Consortium }\end{array}$} & EC-EARTH consortium & EC-EARTH3 & $0.703^{\circ} \times 0.703^{\circ}$ \\
\hline & & EC-EARTH3-Veg & $0.703^{\circ} \times 0.703^{\circ}$ \\
\hline & & $\begin{array}{l}\text { EC-EARTH3- } \\
\text { Veg-LR }\end{array}$ & $1.125^{\circ} \times 1.25^{\circ}$ \\
\hline \multirow[t]{2}{*}{ CAS } & Chinese Academy of Sciences, China & FGOALS-f3-L & $1^{\circ} \times 1^{\circ}$ \\
\hline & & FGOALS-g3 & $2.25^{\circ} \times 2^{\circ}$ \\
\hline \multirow[t]{2}{*}{ NOAA/GFDL } & $\begin{array}{l}\text { National Oceanic and Atmospheric Administration, } \\
\text { Geophysical Fluid Dynamics Laboratory, United States }\end{array}$ & GFDL CM4 & $1^{\circ} \times 1^{\circ}$ \\
\hline & & GFDL-ESM4 & $1^{\circ} \times 1.25^{\circ}$ \\
\hline \multirow[t]{3}{*}{ MOHC } & Met Office Hadley Centre, United Kingdom & $\begin{array}{l}\text { HadGEM3- } \\
\text { GC31-LL }\end{array}$ & $1.25^{\circ} \times 1.875^{\circ}$ \\
\hline & & $\begin{array}{l}\text { HadGEM3- } \\
\text { GC31-MM }\end{array}$ & $0.556^{\circ} \times 0.833^{\circ}$ \\
\hline & & UKESM1.0-LL & $1.25^{\circ} \times 1.875^{\circ}$ \\
\hline \multirow[t]{2}{*}{ INM } & $\begin{array}{l}\text { Institute for Numerical Mathematics, Russian Academy of } \\
\text { Science, Russia }\end{array}$ & INM-CM4.8 & $1.5^{\circ} \times 2^{\circ}$ \\
\hline & & INM-CM5.0 & $1.5^{\circ} \times 2^{\circ}$ \\
\hline IPSL & Institute Pierre Simon Laplace, France & IPSL-CM6A-LR & $1.259^{\circ} \times 2.5^{\circ}$ \\
\hline NIMS/KMA & $\begin{array}{l}\text { National Institute of Meteorological Sciences/Korea } \\
\text { Meteorological Administration, South Korea }\end{array}$ & KACE-1.0-G & $1.25^{\circ} \times 1.875^{\circ}$ \\
\hline KIOST & Korea Institute of Ocean Science and Technology, South Korea & KIOST-ESM & $1.875^{\circ} \times 1.875^{\circ}$ \\
\hline \multirow[t]{2}{*}{ MIROC } & $\begin{array}{l}\text { Japan Agency for Marine-Earth Science and Technology, } \\
\text { Atmosphere and Ocean Research Institute, The University of } \\
\text { Tokyo, National Institute for Environmental Studies, RIKEN } \\
\text { Center for Computational Science, Japan }\end{array}$ & MIROC6 & $1.406^{\circ} \times 1.406^{\circ}$ \\
\hline & & MIROC-ES2L & $2.8125^{\circ} \times 2.8125^{\circ}$ \\
\hline $\begin{array}{l}\text { HAMMOZ- } \\
\text { Consortium }\end{array}$ & HAMMOZ-Consortium, Germany & $\begin{array}{l}\text { MPI-ESM- } \\
\text { 1.2-HAM }\end{array}$ & $1.875^{\circ} \times 1.875^{\circ}$ \\
\hline MPI-M & Max Planck Institute for Meteorology, Germany & MPI-ESM1.2-LR & $1.875^{\circ} \times 2.5^{\circ}$ \\
\hline DKRZ & $\begin{array}{l}\text { German Climate Computing Centre (Deutsches } \\
\text { Klimarechenzentrum), Germany }\end{array}$ & MPI-ESM1.2-HR & $0.938^{\circ} \times 0.938^{\circ}$ \\
\hline MRI & Meteorological Research Institute, Japan & MRI-ESM2.0 & $1.125^{\circ} \times 1.125^{\circ}$ \\
\hline NUIST & $\begin{array}{l}\text { Nanjing University of Information Science and } \\
\text { Technology, China }\end{array}$ & NESM3 & $1.875^{\circ} \times 1.875^{\circ}$ \\
\hline \multirow[t]{3}{*}{ NCC } & NorESM Climate modeling Consortium, Norway & NorCPM1 & $71.875^{\circ} \times 2.5^{\circ}$ \\
\hline & & NorESM2-LM & $1.875^{\circ} \times 2.5^{\circ}$ \\
\hline & & NorESM2-MM & $0.938^{\circ} \times 1.25^{\circ}$ \\
\hline SNU & Seoul National University, South Korea & SAM0-UNICON & $0.938^{\circ} \times 1.25^{\circ}$ \\
\hline
\end{tabular}


TABLE 2. Definitions of the extreme precipitation indices used in the study.

\begin{tabular}{|c|c|c|c|}
\hline Index & Descriptive name & Definition & Units \\
\hline Total wet-day precipitation & PRCPTOT & $\begin{array}{l}\text { Let } \mathrm{RR}_{i j} \text { be the daily precipitation amount on day } i \text { in period } j . \text { If } N \\
\text { represents the number of days in } j \text {, then } \operatorname{PRCPTOT}_{j}=\sum_{n=1}^{N} \mathrm{RR}_{j}\end{array}$ & $\mathrm{~mm}$ \\
\hline Very wet-day precipitation & R95p & $\begin{array}{l}\text { Let } \mathrm{RR}_{w j} \text { be the daily precipitation amount on a wet day } w(\mathrm{RR} \geq \\
1.0 \mathrm{~mm}) \text { in period } j \text { and let } \mathrm{RR}_{w n} 95 \text { be the } 95 \text { th percentile of } \\
\text { precipitation on wet days in the } 1961-90 \text { period. If } W \text { represents the } \\
\text { number of wet days in the period, } \\
\text { then } \mathrm{R} 95 \mathrm{p}_{j}=\sum_{w=1}^{W} R_{w j}, \quad R_{w j}>R_{w n} 95\end{array}$ & $\mathrm{~mm}$ \\
\hline Simple daily intensity index & SDII & $\begin{array}{l}\text { Let } \mathrm{RR}_{w j} \text { be the daily precipitation amount on a wet day } w(\mathrm{RR} \geq \\
1 \mathrm{~mm}) \text { in period } j . \text { If } W \text { represents number of wet days in } j, \\
\text { then } \operatorname{SDII}_{j}=\left(\sum_{w=1}^{W} \mathrm{RR}_{w j}\right) / W\end{array}$ & $m m$ day $^{-1}$ \\
\hline Consecutive dry days & CDD & $\begin{array}{l}\text { Let } \mathrm{RR}_{i j} \text { be the daily precipitation amount on day } i \text { in period } j \text {. Count } \\
\text { the largest number of consecutive days where } \mathrm{RR}_{i j}<1 \mathrm{~mm}\end{array}$ & days \\
\hline
\end{tabular}

and interpolation are more suitable for model evaluation (Alexander et al. 2006). Thus, a daily gridded precipitation dataset for the period 1958-2014 with a resolution of $0.25^{\circ} \times$ $0.25^{\circ}$ provided by the Asian Precipitation-Highly Resolved Observational Data Integration Towards Evaluation of Water Resources (APHRODITE) project (Yatagai et al. 2012) was employed as observation to evaluate the historical simulations of the CMIP6 models in this study. The spatial coverage of this dataset is $15^{\circ} \mathrm{S}-55^{\circ} \mathrm{N}, 60^{\circ}-150^{\circ} \mathrm{E}$ (available at http:// aphrodite.st.hirosaki-u.ac.jp/download/). For consistency, the extreme precipitation indices based on the observations and model output were first calculated on their native grids, before being interpolated to a common $1^{\circ}$ latitude $\times 1^{\circ}$ longitude grid using bilinear interpolation (Ou et al. 2013; Zhang et al. 2013).

To detect possible causes of model bias, monthly horizontal winds, specific humidity, surface pressure and vertical velocity from the 40 CMIP6 models for the period 1958-2014 were utilized. For comparison, the Japanese 55-year Reanalysis (JRA55) dataset, produced by the Japan Meteorological Agency (Ebita et al.2011), was employed as the observations for the same time span. (The JRA-55 dataset can be downloaded from https:// jra.kishou.go.jp/JRA-55/index_en.html.) Similar to the precipitation data, these meteorological fields from all models and reanalysis products were first interpolated to a resolution of $1^{\circ} \times 1^{\circ}$.

\section{c. Extreme precipitation indices}

Following the definition from the Expert Team on Climate Change Detection and Indices (ETCCDI; Zhang et al. 2011), four extreme precipitation indices (Table 2) were used in this study. These were total wet-day precipitation (PRCPTOT), precipitation of very wet days (R95p), simple daily intensity index (SDII), and consecutive dry days (CDD). These four extreme precipitation indices can reflect the basic characteristics of precipitation and its extremes and have been widely used in previous studies (Alexander and Arblaster 2009; Sillmann et al. 2013; Jiang et al. 2015; Sun et al. 2015; Ge et al. 2017; Kim et al. 2020). More details of these extreme precipitation indices can be obtained at the ETCCDI website (http://etccdi.pacificclimate.org/ indices.shtml). It should be noted that the calculation of four extreme precipitation indices for a certain period (month, year, or rainy season) was based on the corresponding daily data in all years of 1958-2014. For R95p calculation, the value of extreme precipitation threshold $\left(\mathrm{RR}_{w n} 95\right)$ in Table 2 was based on the corresponding daily data during same month or rainy season in all years of 1961-90 in our study. We also checked the results when the threshold value was based on all the daily data of 1961-90, which remained unchanged.

\section{d. Model performance metrics}

\section{1) TAYLOR DIAGRAM}

We used the Taylor diagram to evaluate the model capacity for reproducing the observed spatial pattern of the extreme precipitation indices. The Taylor diagram provides a concise comparison between simulations and observations based on the pattern correlation coefficient, centered pattern root-meansquare (RMS) difference, and the ratio of the spatial standard deviations of the modeled and observed values (Taylor 2001). The more skillful the model in reproducing the spatial pattern of the observational extreme precipitation indices, the closer the centered RMS difference is to 0, and the closer both the spatial correlation and ratio of spatial standard deviations are to 1 .

\section{2) INTERANNUAL VARIABILITY SKILL SCORE}

As for the temporal variation, Chen et al. (2011) defined the interannual variability skill (IVS) score as follows:

$$
\mathrm{IVS}=\left(\frac{\mathrm{STD}_{m}}{\mathrm{STD}_{o}}-\frac{\mathrm{STD}_{o}}{\mathrm{STD}_{m}}\right)^{2}
$$

where $\mathrm{STD}_{m}$ and $\mathrm{STD}_{o}$ are the interannual standard deviations of the model simulations and observations, respectively. The calculations of $\mathrm{STD}_{m}$ and $\mathrm{STD}_{o}$ are based on yearly data (Jiang et al. 2015; You et al. 2017). A smaller IVS value implies better model simulation.

\section{3) COMPREHENSIVE RATING METRICS}

On the basis of the Taylor diagram and the IVS values, each extreme precipitation index was used to rank all the models 
(a) South China

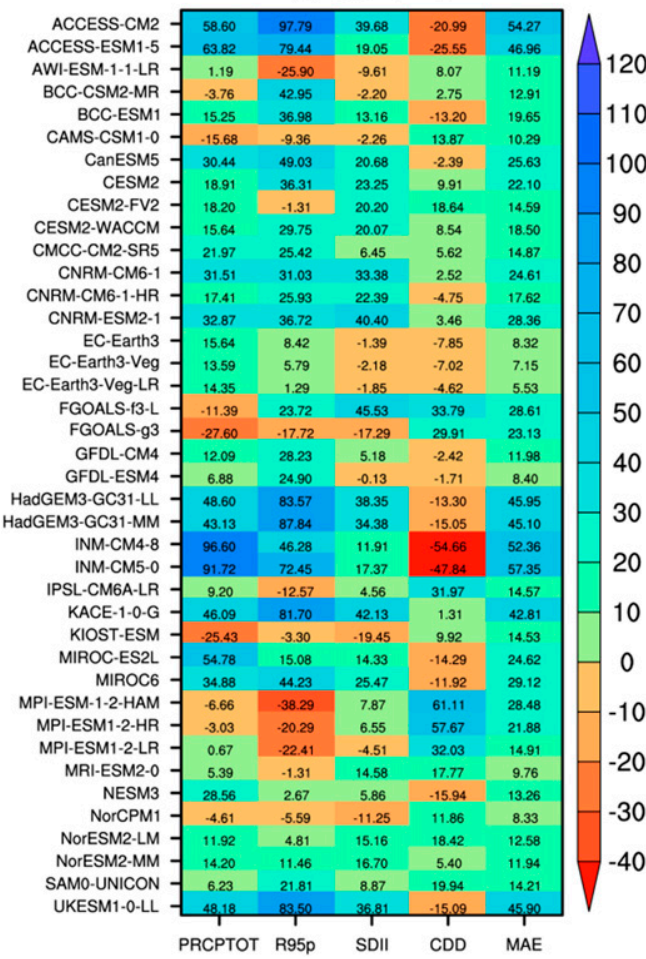

(b) Indochina

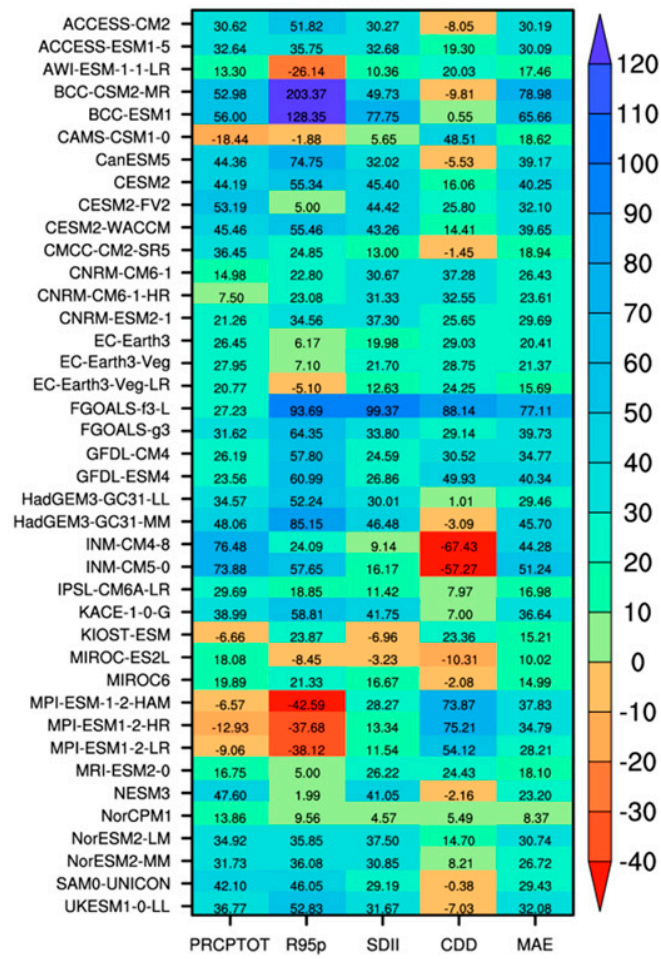

FIG. 2. Relative errors of four extreme precipitation indices simulated by 40 CMIP6 models averaged over (a) South China and (b) Indochina during 1958-2014 [relative error $=($ modeled - observed $) /$ observed $\times 100$ ]. The numbers within the shaded boxes correspond to the values of relative errors. The MAE for each model is given in the right-hand column of each plot.

based on their spatial and temporal simulation capabilities. A comprehensive ranking metric (MR; Jiang et al. 2015) was calculated for the spatial simulation capability and then for the temporal capability. MR is defined as follows:

$$
\mathrm{MR}=1-\frac{1}{n m} \sum_{i=1}^{n} \operatorname{rank}_{i},
$$

where $m$ is the number of models, $n$ is the number of extreme precipitation indices, and $\operatorname{rank}_{i}$ is the model rank for the $i$ th extreme precipitation index. Here, the maximum value of $\operatorname{rank}_{i}$ is 40 , and the minimum value is 1 . The better the model performance, the smaller the value of $\operatorname{rank}_{i}$. Therefore, the closer $\mathrm{MR}$ is to 1 , the better the model performance is.

\section{Model evaluation}

The performance of each model in reproducing the spatial pattern and temporal variability of the extreme precipitation indices in South China and Indochina was assessed separately.

\section{a. Regional averages of the four extreme precipitation indices over the two subregions}

To roughly analyze the model capacity to simulate the extreme precipitation indices in the INCSC region, the relative errors [relative error $=($ modeled - observed $) /$ observed $\times$
100] between the observations and model output in South China and Indochina were first calculated separately (Fig. 2). Figure 2 is a color-coded "portrait diagram" showing the relative errors for all extreme indices in each model, in which both the color shading and the number shown in each box correspond to the value of the relative error. Some important features can be clearly observed. First, most of the CMIP6 models overestimate the annual precipitation, annual extreme precipitation, and precipitation intensity over South China, given that the relative errors of PRCPTOT, R95p, and SDII are positive for most of the models (Fig. 2a). This result is similar with that of Zhu et al. (2020). For Indochina, a wet bias is also prevalent, with positive relative errors for PRCPTOT, R95p, and SDII in most of the models (Fig. 2b). Second, the R95p, SDII, and CDD relative error ranges are larger for Indochina than they are for South China. For instance, the R95p relative errors vary from $-38.29 \%$ to $97.79 \%$ in South China, while the range is $-42.59 \%$ to $203.37 \%$ in Indochina. However, the range of the PRCPTOT relative error is larger for South China than for Indochina, which varies from $-18.44 \%$ to $76.48 \%$ in Indochina and from $-27.6 \%$ to $96.6 \%$ in South China. Third, nearly half of the models present negative biases for CDD in South China, indicating the number of wet days is overestimated in these models.

The results also indicate that there is no evident consistency in the performance of models from the same modeling center, such as those from the Beijing Climate Center (BCC), National 

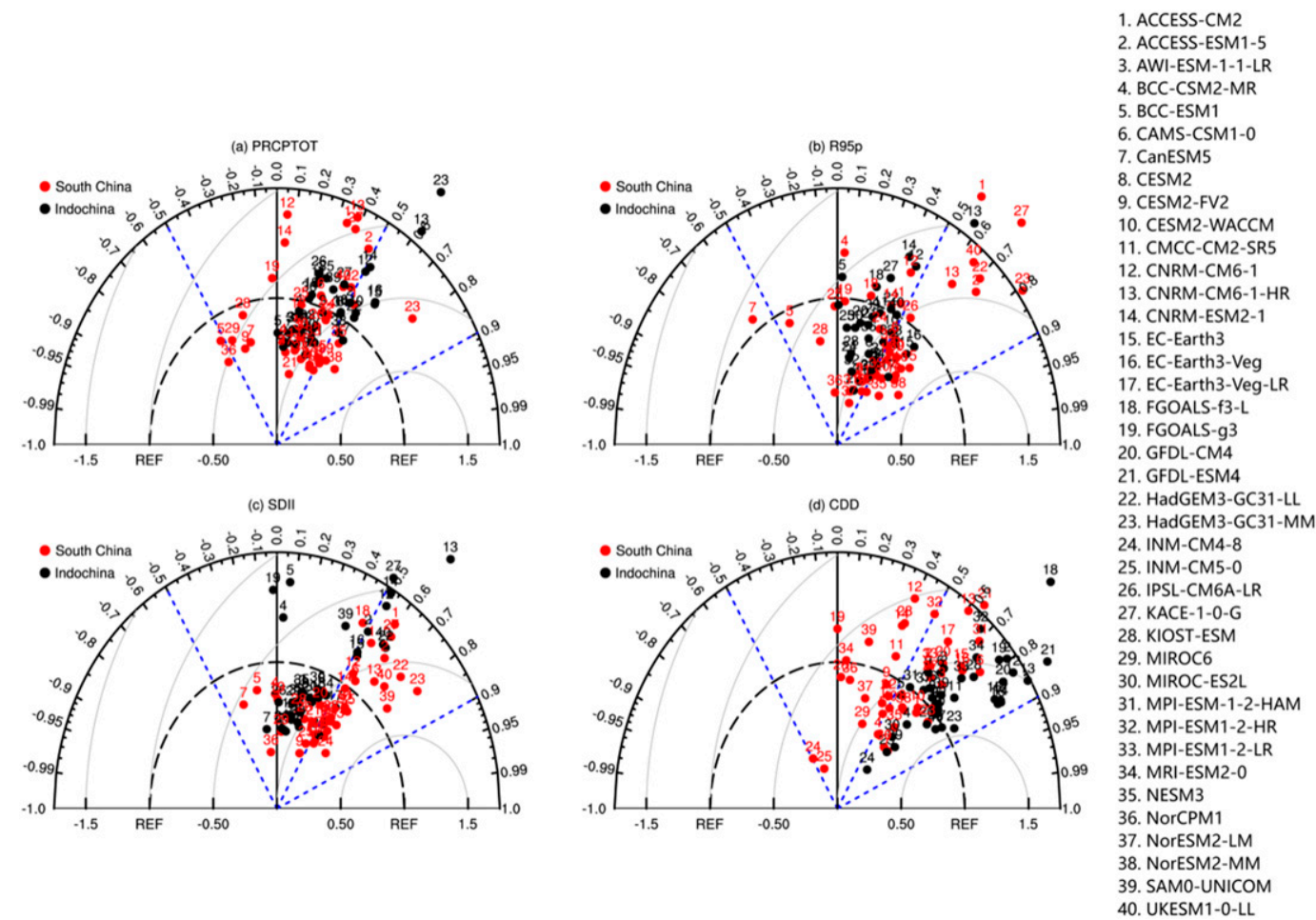

40. UKESM1-0-LL

FIG. 3. Taylor diagrams of four extreme precipitation indices showing the results for 40 CMIP6 models for South China (red dots) and Indochina (black dots). The angular axis represents the model-observation spatial correlation coefficient, and the radial axis represents the normalized spatial standard deviation (RMS deviation) against the observations. Each dot represents a CMIP6 model, which is identified by the corresponding number.

Oceanic and Atmospheric Administration (NOAA/GFDL), and the Chinese Academy of Sciences (CAS). Moreover, the influence of model horizontal resolution on the simulation of extreme precipitation indices is discrepant between South China and Indochina. For example, a comparison of the performance of NorESM2-LM and NorESM2-MM reveals that, for South China, the lower-resolution models seem to have a better simulation skill with regards to PRCPTOT and SDII than the higher-resolution models. On the contrary, the higher-resolution models have smaller relative errors for PRCPTOT and SDII in Indochina compared with the lowerresolution models.

In general, most of the CMIP6 models reproduce the extreme indices more accurately for South China than for Indochina, with smaller relative errors. To gain an overall appreciation of this effect, the mean absolute value of the relative errors (MAE; right-hand column in Figs. 2a,b) was calculated for each model. Based on the MAEs, EC-EARTH3, ECEARTH3-Veg, EC-EARTH3-Veg-LR, GFDL-ESM4, MRIESM2.0, and NorCPM1 have the highest skill for South China among the models, with relative errors less than $10 \%$. However, the extreme indices for Indochina are relatively poorly simulated by nearly all models except NorCPM1.

\section{b. Evaluation of spatial variation}

The climatological spatial distributions of the four extreme precipitation indices in the observation and 40 CMIP6 models for the period 1958-2014 are shown in Figs. S1-S4 in the online supplemental material. The observed climatological spatial distributions are similar for PRCPTOT [Fig. S1a(0)], R95p [Fig. S2a(0)], and SDII [Fig. S3a(0)]. Large areas of annual precipitation, annual extreme precipitation, and precipitation density appear along the western coast and eastern coast regions of Indochina. The southeast slope of the Tibetan Plateau and central Myanmar are the regions with small values of annual precipitation, annual extreme precipitation, and precipitation density [Figs. S1a(0), S2a(0), and S3a(0)]. However, the high numbers of consecutive dry days are mainly located in southern Myanmar [Fig. S4a(0)]. Most of the models have difficulty in capturing the observed spatial pattern of the four extreme precipitation indices (Figs. S1-S4). To present a concise summary in this paper of the simulation skills with respect to the spatial pattern of the four indices over South China and Indochina, Taylor diagrams are used. Figure 3 shows a Taylor diagram for each of the four extreme precipitation indices based on the model simulations and the observations, with red dots for South China and black dots for Indochina. The spatial correlation coefficients of most CMIP6 models vary between 0.5 and 0.9 (dotted blue radial lines) for SDII in South China (Fig. 3c). However, the spatial correlation coefficients of half of the models are smaller than 0.5 for R95p and CDD (Figs. 3b,d) and nearly all models perform poorly for PRCPTOT in South China (Fig. 3a). This indicates that most CMIP6 models possess limited simulation skill for 
(a) South China

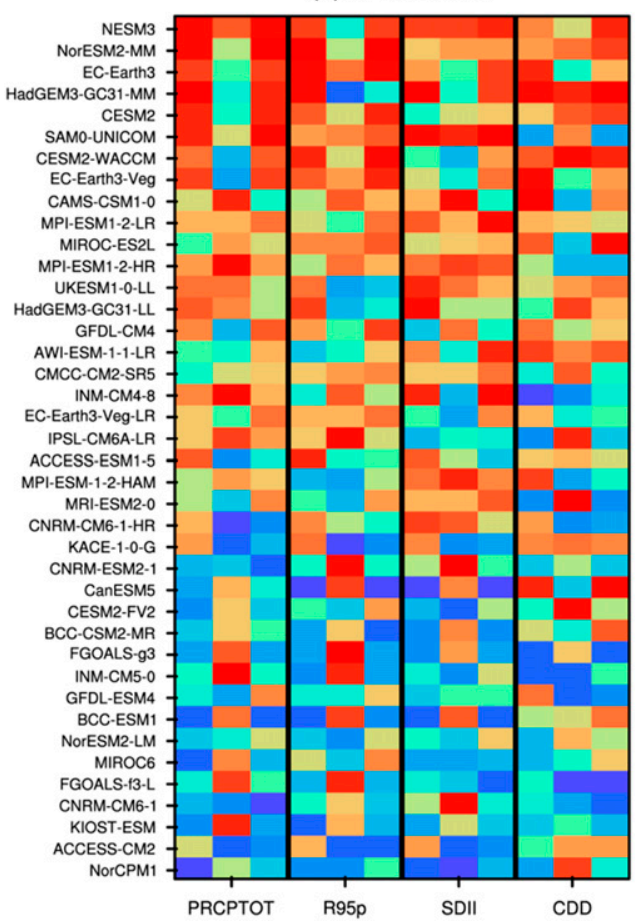

(b) Indochina

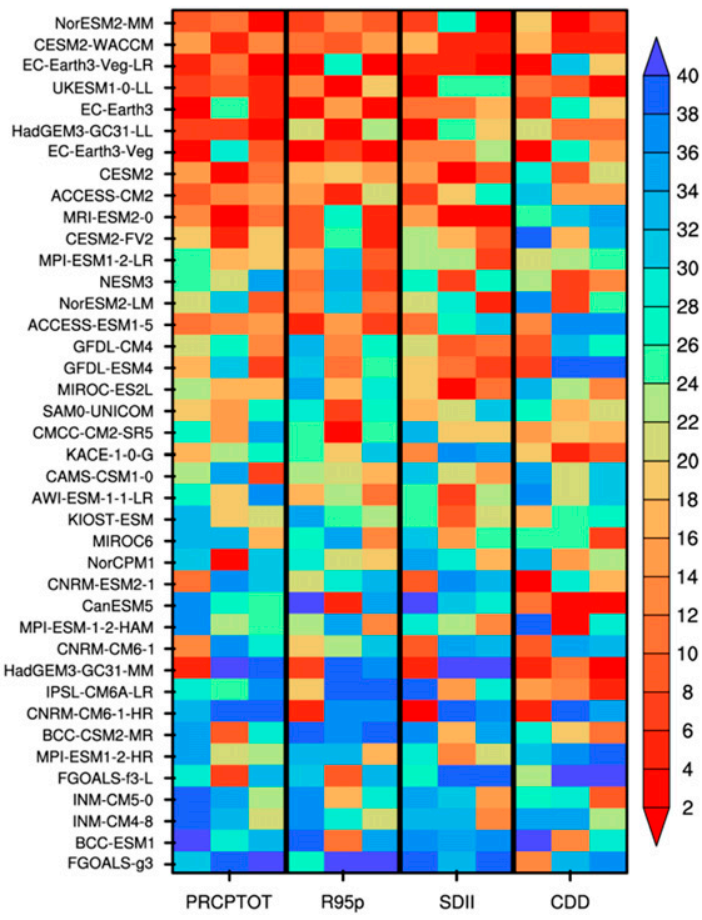

FIG. 4. Portrait diagram of the model rankings (given by the color) for each extreme precipitation index based on the spatial correlation (left-hand columns), spatial standardized deviation ratio (center columns), and centered normalized RMS difference (right-hand columns) for (a) South China and (b) Indochina. The model names are listed on the left.

extreme precipitation indices except SDII in South China. For Indochina, the spatial correlation coefficients of all CMIP6 models are larger than 0.5 for CDD (Fig. 3d), whereas threequarters of the models fail to simulate the spatial patterns of PRCPTOT, R95p, and SDII, with spatial correlation coefficients smaller than 0.5 (Figs. 3a,b,d). These results indicate that the CMIP6 models only simulate well the spatial distribution of CDD in Indochina. Most of the models have a ratio of variance for PRCPTOT, R95p, and SDII that is less than 1 (Figs. 3a-c), whereas half of the models have a ratio of variance for CDD that is larger than 1 (Fig. 3d) in South China. This implies that most models underestimate the spatial variation of annual precipitation, annual extreme precipitation, and precipitation intensity, but half of them overestimate the spatial variation of consecutive dry days over South China. For Indochina, most models have a ratio of variance for R95p and SDII that is less than 1 but larger than 1 for $\mathrm{CDD}$, and half of them have a ratio of variance for PRCPTOT that is larger than 1 . This indicates that most models underestimate the spatial variation of annual extreme precipitation and precipitation intensity but overestimate the spatial variation of consecutive dry days over Indochina. For both South China and Indochina, the majority of models have centered normalized RMS differences (gray solid lines) for PRCPTOT that are larger than 1 (Fig. 3a), indicating that the amplitude of the biases for annual extreme precipitation are large over the INCSC region. In addition, the relatively concentrated distributions in the Taylor diagrams imply a relatively small intermodel spread for all indices over the INCSC region (Figs. 3a-d).

In summary, CMIP6 models perform relatively poorly in simulating the spatial pattern of the extreme precipitation indices both in South China and Indochina. Compared with other indices, SDII is better simulated in South China, while CDD is well simulated in Indochina by these 40 CMIP6 models. In general, the spatial variations of extreme precipitation indices are better simulated in South China than in Indochina.

Figure 4 shows model rankings for each of the four extreme precipitation indices with regards to their pattern correlation coefficient (left-hand column), ratio of standard deviations (center column), and centered normalized RMS difference (right-hand column), for each extreme index. The exact values of each statistic are shown in Tables S1 and S2 for reference. In Fig. 4, models with more red boxes are more skillful; and conversely, models with more blue boxes are less skillful. The ranks of the three metrics (pattern correlation coefficient, spatial standardized deviation ratio, and centered normalized RMS difference) obtained from the Taylor diagrams for each extreme precipitation index are first averaged model by model. Then, the obtained values are sorted as the basis for the MR calculation to quantify the capability of each CMIP6 model in reproducing the spatial pattern of observations. The application of MR, which was introduced in section 2, provides a comprehensive spatial ranking for each model. According to the values of the spatial MR, the five leading models for 
(a) IVS in South China

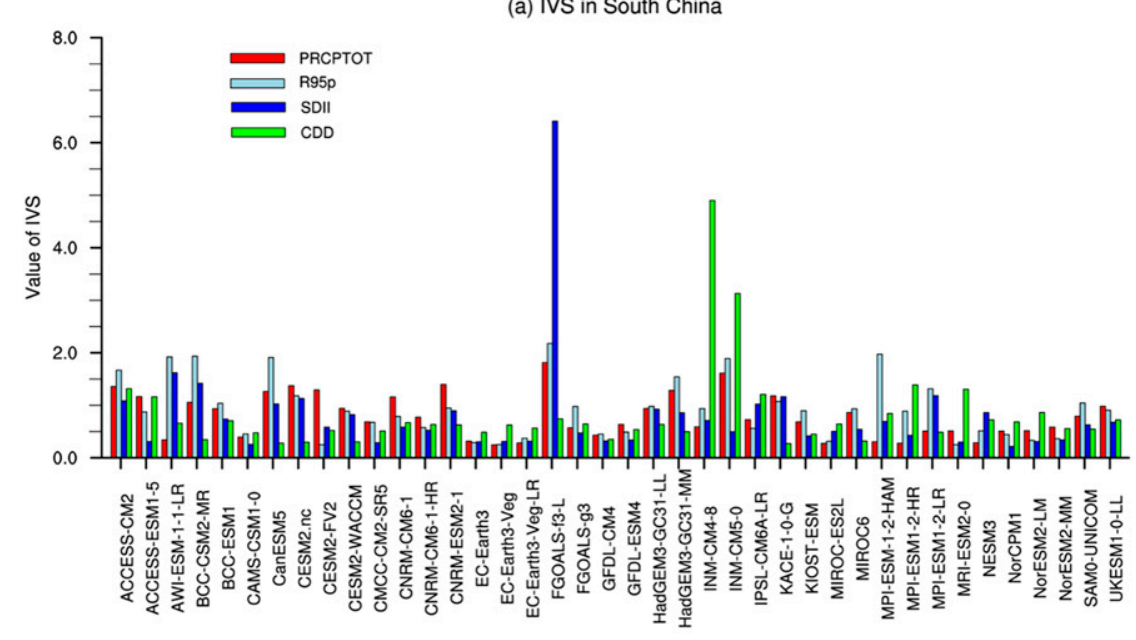

(b) IVS in Indochina

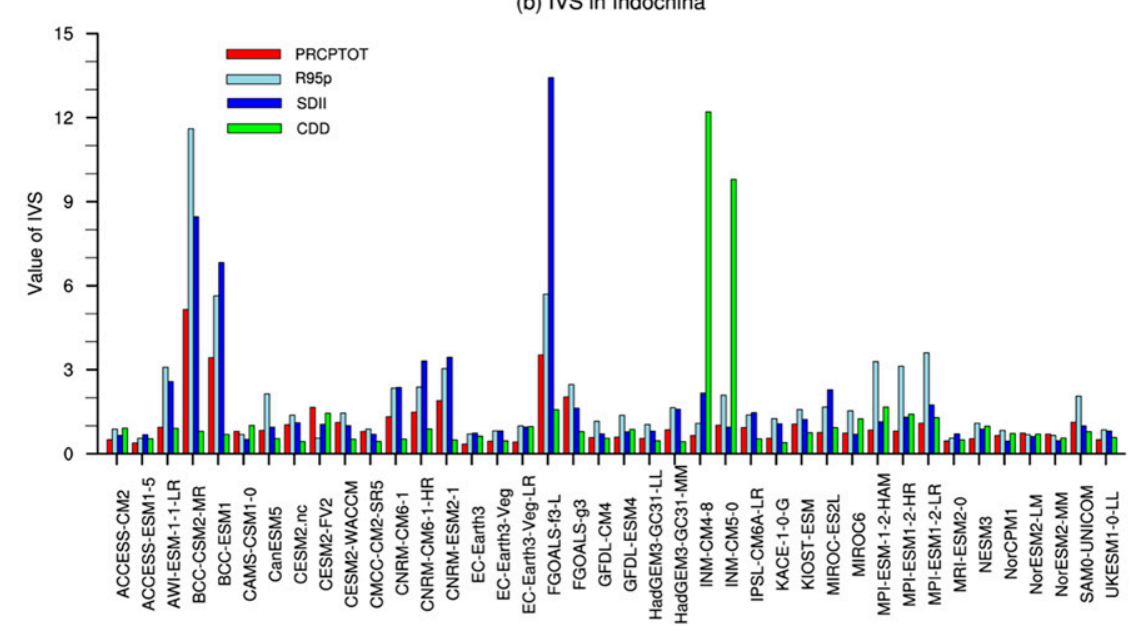

FIG. 5. CMIP6 model IVS scores for four extreme precipitation indices over (a) South China and (b) Indochina.

simulations in South China are NESM3, NorESM2-MM, ECEARTH3, HadGEM3-GC31-MM, and CESM2. For Indochina, meanwhile, NorESM2-MM, CESM2(WACCM), EC-EARTH3Veg-LR, UKESM1.0-LL, and EC-EARTH3 are the five models with the most skillful spatial pattern simulation capacity. Therefore, two models (NorESM2-MM and EC-EARTH3) possess better simulation skills for the spatial pattern of extreme precipitation compared with other models over the whole INCSC region.

\section{c. Evaluation of interannual variability}

In addition to the spatial patterns, examining the model capacity for simulating the temporal variation of extreme precipitation indices is also an important aspect of model evaluation. We used the IVS skill score introduced in section $2 \mathrm{c}$ to measure the similarity between the interannual variability of the modeled and observed extreme precipitation indices. The model IVS scores for the four extreme precipitation indices averaged over the two subregions of the INCSC were calculated for 1958-2014 (Tables S3 and S4) and are shown in Fig. 5. The interannual variability of all indices is generally better simulated for South China than for Indochina, as the range of IVS values is smaller in South China (Fig. 5a). For example, the IVS scores for R95p range from 0 to 3 for South China (Fig. 5a), but they vary from 0 to 12 for Indochina (Fig. 5b).

For South China (Fig. 5a), the interannual variability of PRCPTOT and R95p are well simulated by most of the CMIP6 models. For SDII, all models except FGOALS-f3-L capture the observed interannual variability well. For CDD, two models (INM-CM4.8 and INM-CM5.0) show limited capacity in capturing the observed interannual variability. For Indochina, however, the simulation skills vary with the indices across the CMIP6 models (Fig. 5b). For example, R95p and SDII generally have the highest IVS values, whereas the IVS values of PRCPTOT and CDD are consistently low across most of the models (Fig. 5b). In general, the majority of the CMIP6 models can better capture the characteristics of the interannual variability of the four extreme precipitation 
(a) MR for South China

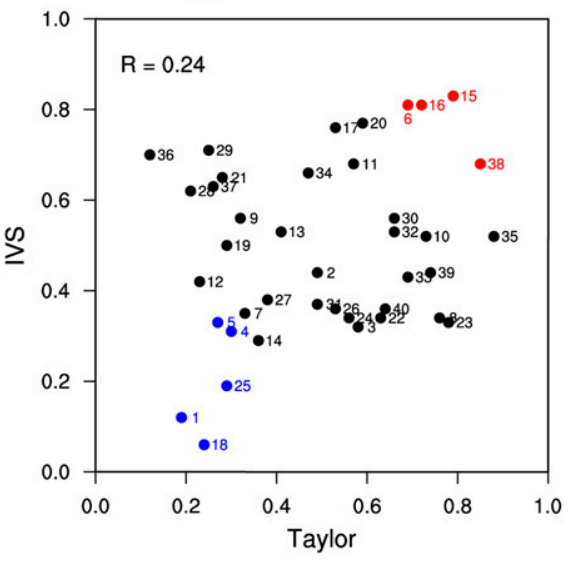

(b) MR for Indochina

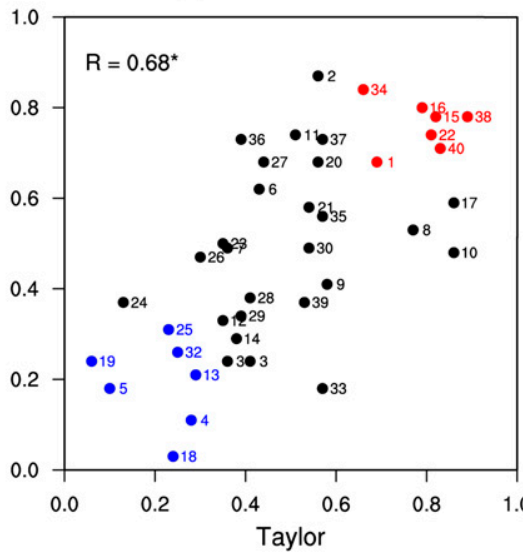

1. ACCESS-CM2

2. ACCESS-ESM1-5

3. AWI-ESM-1-1-LR

4. BCC-CSM2-MR

5. BCC-ESM1

6. CAMS-CSM1-0

7. CanESM5

8. CESM2

10. CESM2-WACCM

11. CMCC-CM2-SR5

12. CNRM-CM6-1

12. CNRM-CM6-1
13. CNRM-CM6-1-HR

13. CNRM-CM6-1-HR
14. CNRM-ESM2-1

14. CNRM-ESM2-1
15. EC-Earth3

16. EC-Earth3-Veg

17. EC-Earth3-Veg-LR

18. FGOALS-f3-L

19. FGOALS-g3

20. GFDL-CM4

21. GFDL-ESM4

22. HadGEM3-GC31-

23.

24. INM-CM4-8

24. INM-CM4-8

25. INM-CM5-0

26. IPSL-CM6A-LR

27. KACE-1-0-G

28. KIOST-ESM

29. MIROC6

30. MIROC-ES2L

31. MPI-ESM-1-2-HAM

32. MPI-ESM1-2-HR

33. MPI-ESM1-2-LR

34. MRI-ESM2-0

35. NESM3

36. NorCPM1

37. NorESM2-LM

37. NorESM2-LM

38. NorESM2-MM

40. UKESM1-0-LL

FIG. 6. Scatter diagrams of the MR scores for each model based on the Taylor diagram ( $x$ axis; spatial pattern) and IVS ( $y$ axis; temporal variability) for (a) South China and (b) Indochina. Each dot represents a CMIP6 model identified by the number on its right. The models in red located in the top-right quadrant are the most skillful models, while the models in blue in the bottom-left quadrant are the least skillful models based on both measures.

indices over South China (Fig. 5a) than they can over Indochina (Fig. 5b).

The value of the temporal MR for each individual model was also calculated, to obtain an overall model evaluation of interannual variability. The five leading models for simulating the interannual variability of extreme precipitation indices over South China are EC-EARTH3, CAMS-CSM1.0, ECEARTH3-Veg, GFDL CM4, and EC-EARTH3-Veg-LR. For Indochina, meanwhile, ACCESS-ESM1.5, MRI-ESM2.0, ECEARTH3-Veg, EC-EARTH3, and NorESM2-MM are the five best-performing models according to the MR scores. The bestperforming models with regards to interannual variability are almost completely different from the best-performing models based on spatial pattern, which means that, among the CMIP6 models used in this study, the skill in simulating the spatial pattern of extreme precipitation is not consistent with the model capability in simulating the interannual variability.

In general, most of the models have a better capacity for simulating the interannual variability of precipitation extremes in South China than in Indochina. Based on the temporal MR scores, the top five models for South China are EC-EARTH3, CAMS-CSM1.0, EC-EARTH3-Veg, GFDL CM4, and ECEARTH3-Veg-LR, while ACCESS-ESM1.5, MRI-ESM2.0, EC-EARTH3-Veg, EC-EARTH3, and NorESM2-MM are the five leading models for Indochina.

\section{d. Overall model ranking}

Owing to the lack of consistency between the model rankings based on their capacity for reproducing the observed spatial pattern and interannual variability of the extreme precipitation indices, it is necessary to take both rankings into account in the quantitative evaluation of extreme precipitation indices in South China and Indochina. Figure 6 shows a scatter diagram of the spatial-pattern MR and the temporal-variability MR. The correlation coefficient between the spatial MR and temporal MR is 0.24 (not statistically significant at the $95 \%$ confidence level) for South China (Fig. 6a) and 0.68 (statistically significant at the $95 \%$ confidence level) for Indochina (Fig. 6b). These results indicate that the simulation of spatial variation is more consistent with the simulation of the interannual variability over Indochina than that over South China by the CMIP6 models.

Based on both the spatial and temporal MRs, which were used to reflect the model capacity in simulating the spatiotemporal variation, the selection criteria for two model ensembles were that (i) models with both MRs greater than 0.65 would be selected as members of A_group, while (ii) models with both MRs less than 0.35 would be selected as members of B_group. Furthermore, if the selection criteria of A_group (B_group) were changed to be greater than 0.55 (less than 0.45), the subsequent analyses showed little difference. According to the selection criteria, four models (CAMS-CSM1.0, ECEARTH3, EC-EARTH3-Veg, and NorESM2-MM) are regarded as the most skillful models for South China (Fig. 6a), while seven models (ACCESS-CM2, EC-EARTH3, EC-EARTH3Veg, HadGEM3-GC31-LL, MRI-ESM2.0, NorESM2-MM, and UKESM1.0-LL) are the leading models for Indochina (Fig. 6b). There are three models (EC-EARTH3, EC-EARTH3-Veg, and 
(a) South China

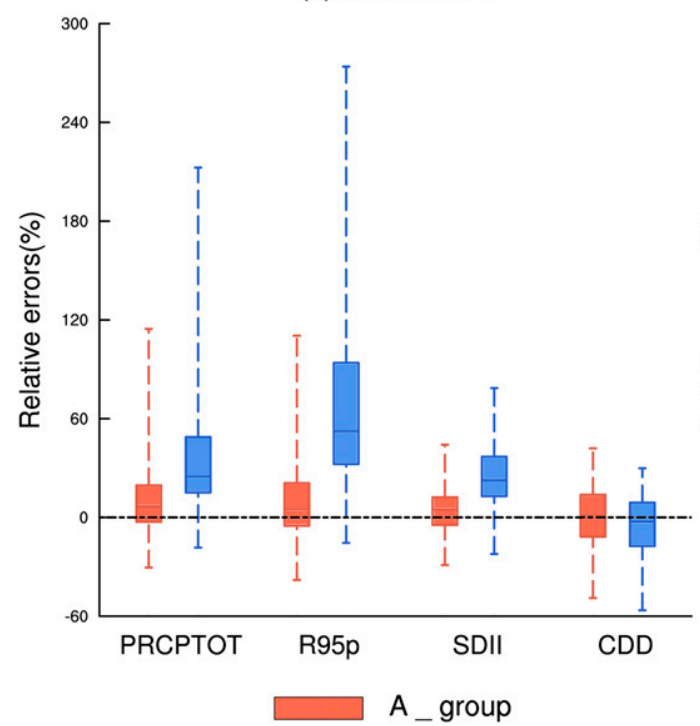

(b) Indochina

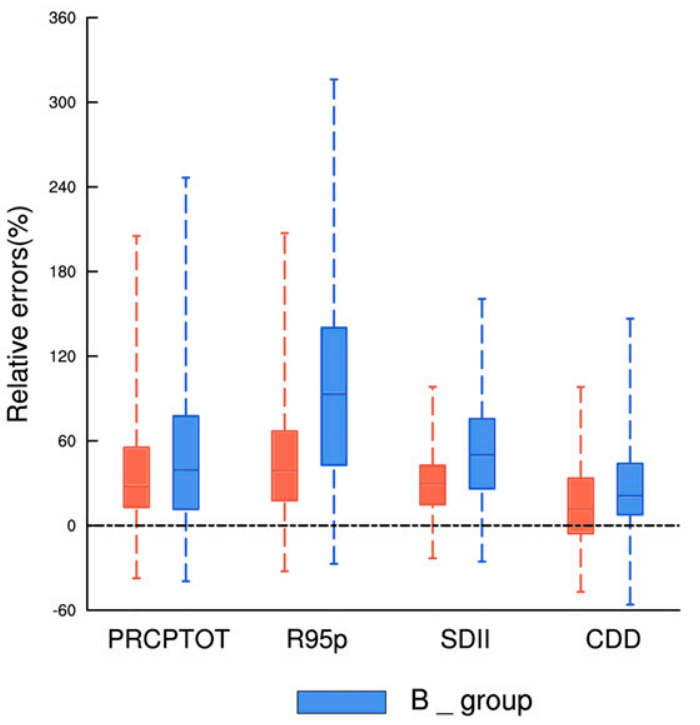

FIG. 7. Box-and-whisker plots of the relative errors of four extreme precipitation indices for A_group and B_group over (a) South China and (b) Indochina. The upper and lower limits of each box represent the 75th- and 25th-percentile values, respectively. The horizontal line in each box represents the ensemble median, and the whiskers indicate the relative error range for the ensemble.

NorESM2-MM) capable of simulating both the spatial pattern and interannual variability well in the INCSC region.

Overall, for South China, four models (CAMS-CSM1.0, ECEARTH3, EC-EARTH3-Veg, and NorESM2-MM) were selected as the members of the most skillful multimodel ensemble (A_group), while five models (ACCESS-CM2, BCC CSM2-MR, BCC-ESM1, FGOALS-f3-L, and INM-CM5.0) made up the least skillful multimodel ensemble (B_group). For Indochina, the A_group included seven models (ACCESSCM2, EC-EARTH3, EC-EARTH3-Veg, HadGEM3-GC31-LL, MRI-ESM2.0, NorESM2-MM, and UKESM1.0-LL), while seven different models (BCC_CSM2-MR, BCC-ESM1, FGOALSf3-L, FGOALS-g3, CNRM-CM6.1-HR, INM-CM5.0, and MPI-ESM1.2-HR) constituted the B_group.

\section{Performance of optimal models}

In the previous section, we identified the most and least skillful models in simulating the extreme precipitation indices for South China and Indochina. In this section, we compare the performances of the A_group and B_group in simulating each extreme precipitation index during the period 1958-2014 for South China (Fig. 7a) and Indochina (Fig. 7b) based on the relative errors presented by box-and-whisker plots.

For South China, the simulations of PRCPTOT, R95p, and SDII by A_group show striking improvement compared with B_group, because the median values are closer to 0 , the ranges are smaller, and the interquartile model ranges are relatively smaller (Fig. 7a). For example, the median value of relative error for $\mathrm{R} 95 \mathrm{p}$ in $\mathrm{B}$ group is $52 \%$ but reduces to $5 \%$ in A_group. The simulations of CDD by A_group also show some improvement, but to a relatively smaller extent (Fig. 7a).
Similar to the result in South China, the simulations of the four extreme precipitation indices by A_group are remarkably improved compared with B_group (Fig. 7b). As the 25thpercentile, median, and 75th-percentile values of relative errors of PRCPTOT, R95p, and SDII for A_group and B_group are all larger than 0 , wet biases over Indochina are apparent in both groups (Fig. 7b).

Figure 8 shows the spatial pattern of the observation and the model biases of the two model ensembles in terms of the four extreme indices over the INCSC region. The model biases of the two model ensembles over South China are the differences between the two model ensembles (A_group and B_group of South China) and the observation, and the same with Indochina. The observed climatological spatial distributions are similar for PRCPTOT (Fig. 8a), R95p (Fig. 8d), and SDII (Fig. 8g). Large areas of annual precipitation, annual extreme precipitation, and precipitation density appear along the western coast and eastern coast regions of Indochina, and the southeast slope of the Tibetan Plateau and central Myanmar are the regions with small values. However, the large CDD values are mainly located in southern Myanmar (Fig. 8j). For South China, the model biases of A_group (Figs. 8b,e,h) are smaller than those of B_group in terms of PRCPTOT, R95p, and SDII, especially along the southeast slope of the Tibetan Plateau and in northern South China. However, A_group shows less annual total precipitation and annual total extreme precipitation over southern South China (Figs. 8b,e), instead of the wet bias in B_group (Figs. 8c,f). Besides, the wet bias in A_group over most of Indochina is significantly reduced compared with B_group. For example, the mean absolute errors for R95p in B_group can reach up to $200 \mathrm{~mm}$ but are less than $200 \mathrm{~mm}$ in A_group over Indochina. 
(a) APHRO

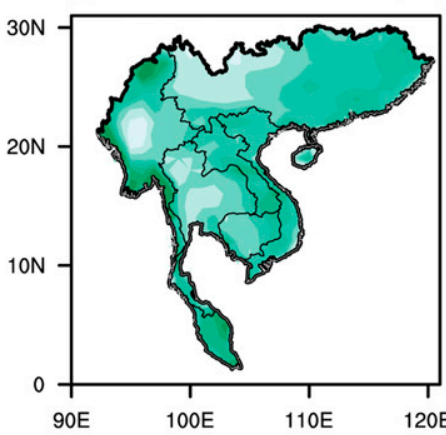

(d) APHRO

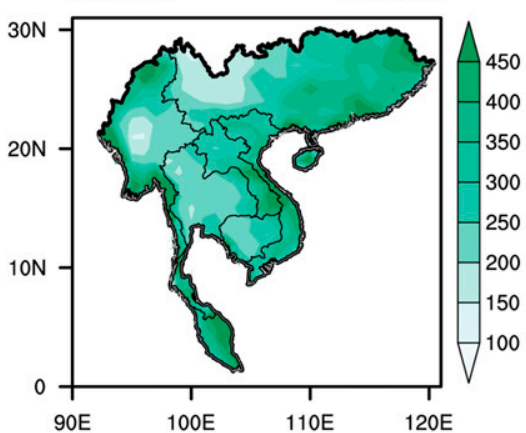

(g) APHRO

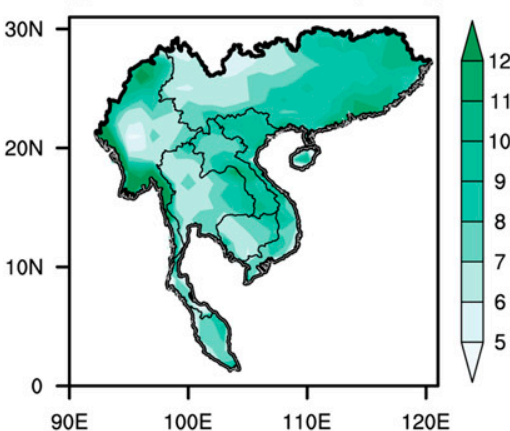

(j) APHRO

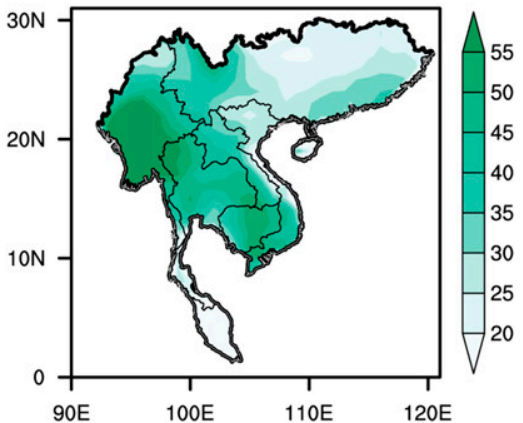

(b) A_group - APHRO PRCPTOT (mm)
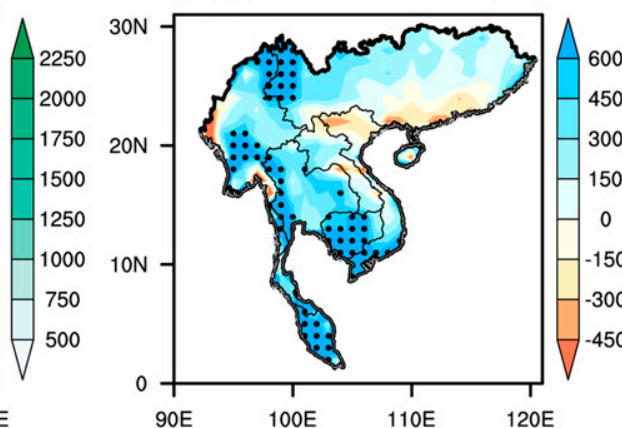

(e) A _ group - APHRO R95p (mm)

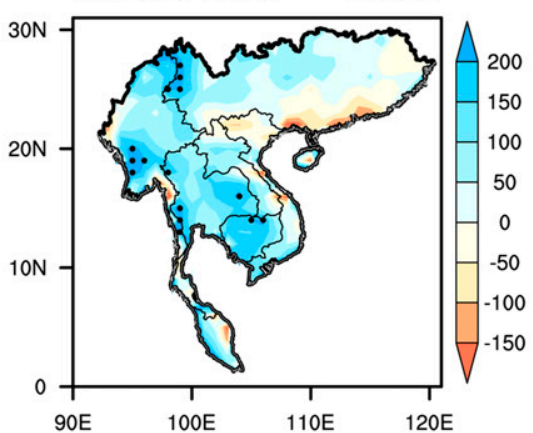

(h) A_group - APHRO SDII (mm/day)

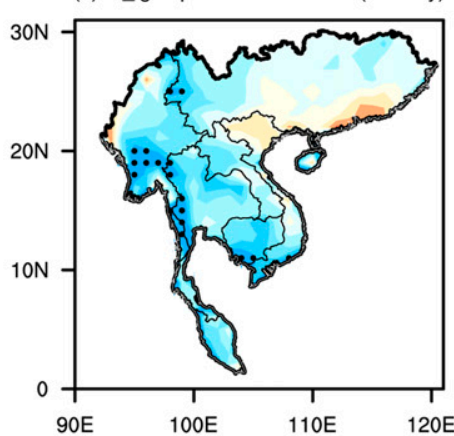

(k) A group - APHRO CDD (days)

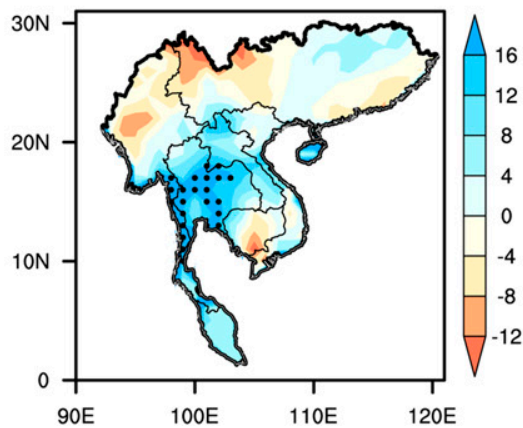

(c) B _ group - APHRO PRCPTOT (mm)

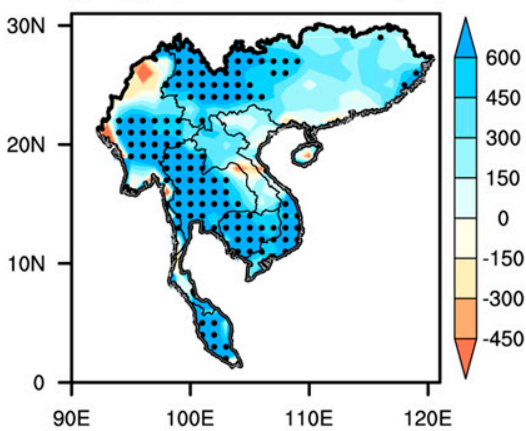

(f) B_group - APHRO R95p (mm)

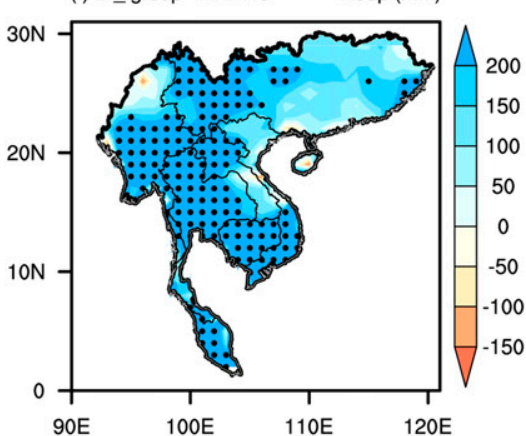

(i) B group - APHRO SDII (mm/day)

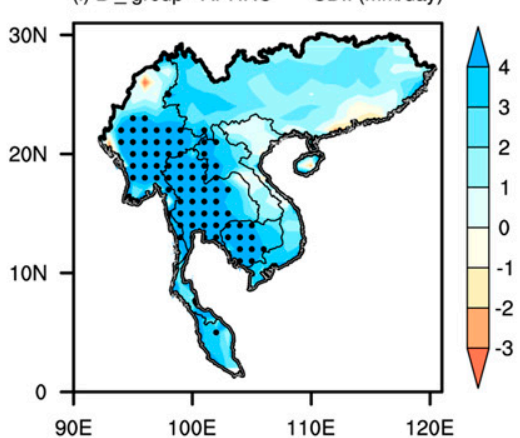

(l) B_group - APHRO CDD (days)

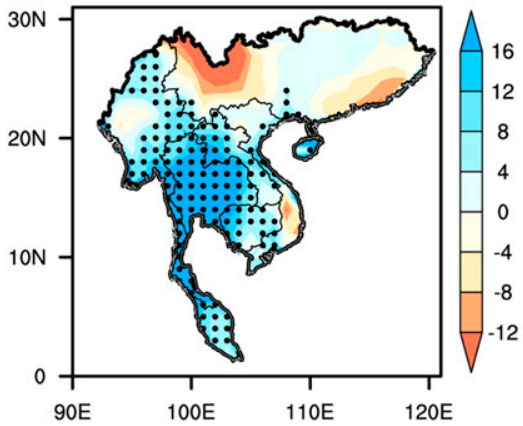

FIG. 8. Spatial distribution of (left) the observation and (center),(right) the model biases of two model ensembles in terms of four extreme precipitation indices (rows) over the INCSC region. The dotted areas in the center and right columns represent the regions where the biases are larger than (b),(c) $500 \mathrm{~mm}$, (e),(f) $200 \mathrm{~mm}$, (h),(i) $4 \mathrm{~mm} \mathrm{day}^{-1}$, and (k),(j) 15 days. 

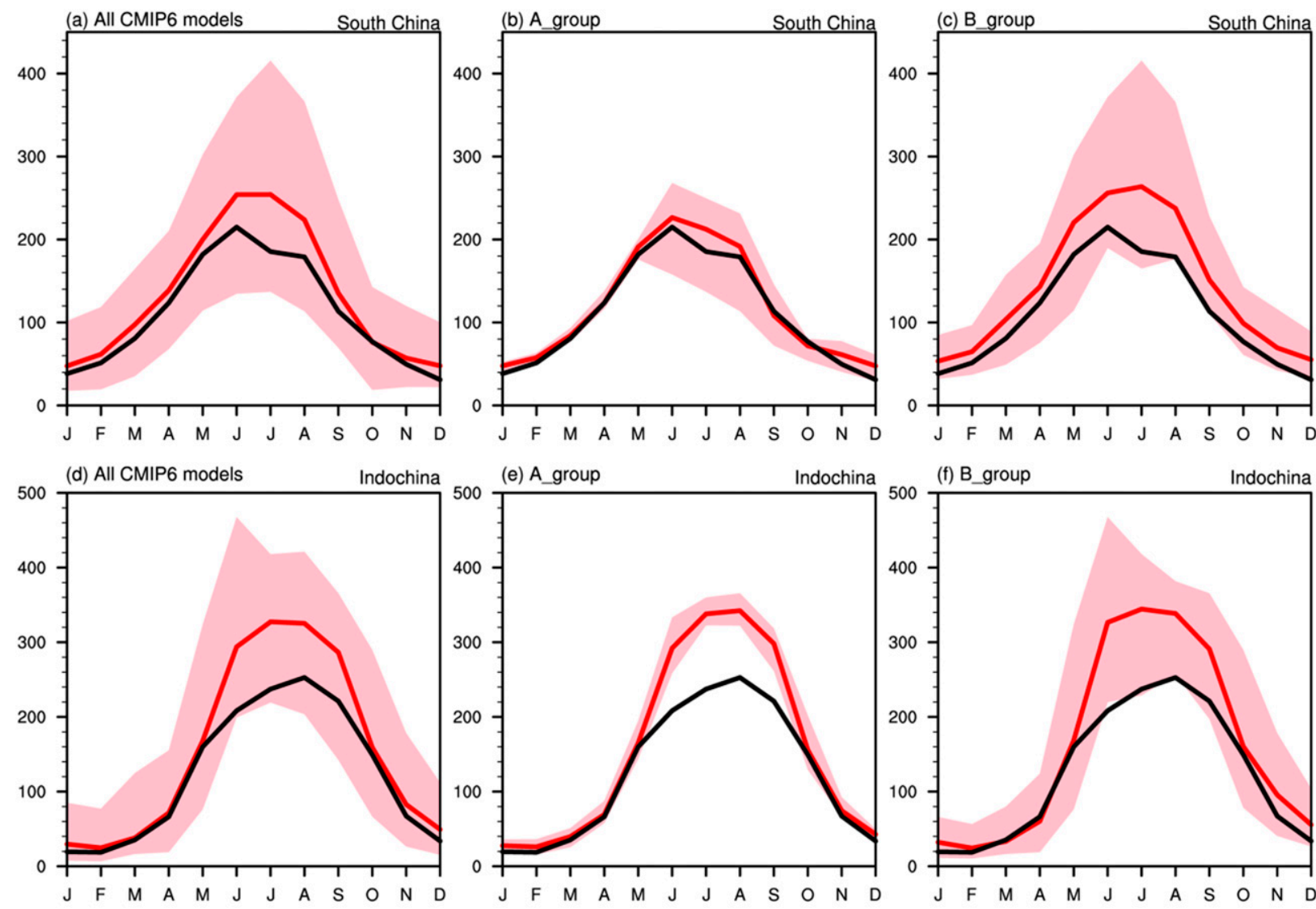

Observation

Ensemble mean

FIG. 9. Annual cycles of PRCPTOT (unit: $\mathrm{mm}$ ) based on observation (black line) and ensemble means (red line) of (a),(d) all CMIP6 models, (b),(e) A_group, and (c),(f) B_group area averaged over South China and Indochina. Pink shading indicates the value range of individual models in each ensemble.

The historical annual cycles (red line) simulated by the ensemble means of all CMIP6 models, A_group, and B_group as well as the observed annual cycle (black line) for PRCPTOT and R95p area averaged over the South China and Indochina are shown in Figs. 9 and 10. All the three ensemble means could briefly capture the basic characteristic of annual cycle for PRCPTOT and R95p over the INCSC region. For South China, the simulated PRCPTOT (Fig. 9b) and R95p (Fig. 10b) by A_group ensemble mean are more realistic than that by other two ensemble means. The model biases of PRCPTOT (Figs. 9a,c) and R95p (Figs. 10a,c) by the ensemble means of all CMIP6 models and B_group mainly occur in the period of April-September, which is traditionally considered as the time of rainy season in South China (Figs. S5 and S6; Yang et al. 2008; Wu et al. 2010; Potty et al. 2012). For Indochina, the annual cycles of three ensemble means show a large model bias from May to October and almost consistent with the observation in other months. The period May to October is also the rainy season in Indochina (Figs. S5 and S6; Mekong River Commission 2010; Chhin et al. 2017). These indicate that the biases of PRCPTOT and R95p between three ensemble means and observation mainly concentrate on April-September and May-October for South China and Indochina, respectively. Therefore, we further investigate the possible causes for the biases in precipitation and extreme precipitation during AprilSeptember for South China and May-October for Indochina in the following analyses.

To investigate the possible causes for the biases in precipitation and extreme precipitation over the INCSC region, the April-September-averaged atmospheric circulations of the two model ensembles (A_group and B_group) were compared with the JRA-55 product. Figure 11 shows the April-September mean meridional wind speed (shaded) and wind vectors at $850 \mathrm{hPa}$ from JRA-55 (Fig. 11a), and the differences between the two model ensembles and JRA-55 (Figs. 11b,c). In the observations (Fig. 11a), four main channels in the lower-layer troposphere bring air to China. The first is the westerly flow that stretches eastward from over the Arabian Sea until it reaches South China. The second is the southerly wind stretching from the western branch of the subtropical high over the western North Pacific and turning over the South China region from the South China Sea. Also, two cross-equatorial 
(a) All CMIP6 models

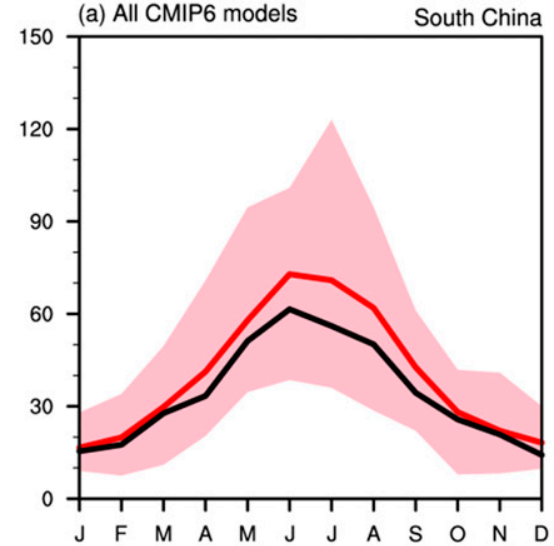

(d) All CMIP6 models

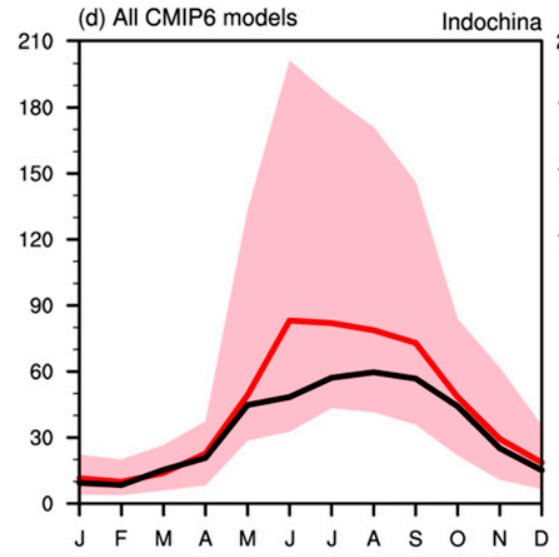

(b) A_group

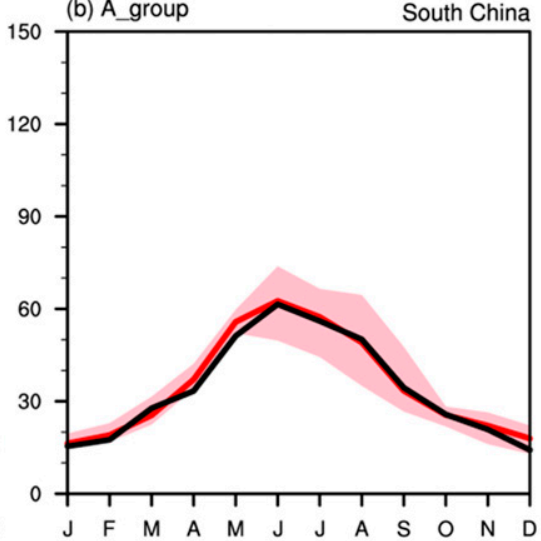

(c) B_group

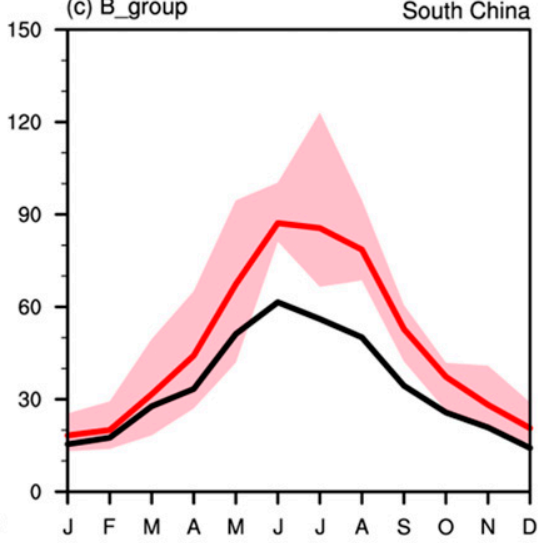

(e) A_group

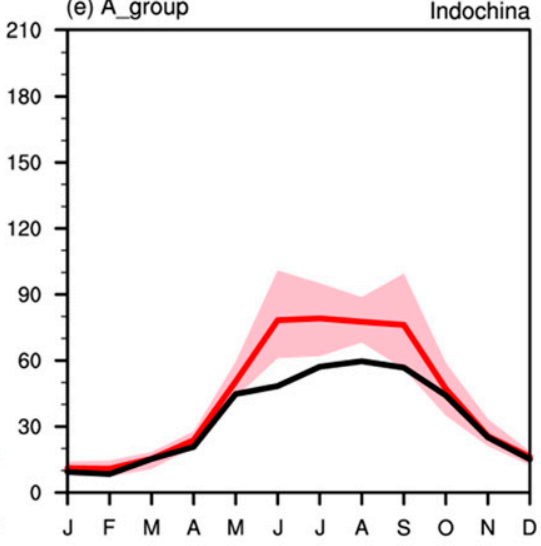

(f) B_group Indochina

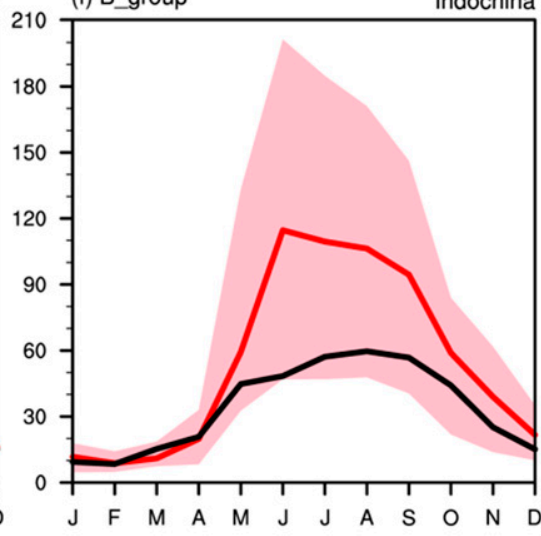

Observation

Ensemble mean

FIG. 10. As in Fig. 9, but for R95p.

flows exist over the Bay of Bengal and South China Sea. All four airflows extend from oceanic regions to the continent, and therefore carry large amounts of water vapor. Thus, these are the main sources of water vapor for precipitation and extreme precipitation in South China (Chi et al. 2005; Zhong et al. 2019). The two ensemble means capture the main features of the observed low-level circulation (figures not shown). However, the meridional wind speed simulated by B_group is overestimated over South China, as evidenced by the positive meridional wind anomalies over the South China region (Fig. 11c). The overestimation of meridional wind speed over South China by the B_group models means that more water vapor is transported to South China, leading to a significant wet bias in South China. This result is similar to the findings of Hui et al. (2018). However, the difference in meridional wind speed between JRA55 and the A_group ensemble is relatively small over South China (Fig. 11b). The relatively well-simulated meridional wind speed by A_group induces the reduction in model bias with respect to water vapor transport, thus bringing it closer to the observation of extreme precipitation than B_group.

The differences in climatological April-September meridional wind speed at $850 \mathrm{hPa}$ between the observation and each model in A_group plus B_group in the period 1958-2014 are shown in Fig. S11, which reflects the model consistency with respect to meridional wind speed simulation in the two model ensembles. The results show that three out of the four models in A_group underestimate the meridional wind speed over the southeast slope of the Tibetan Plateau, inducing the reduced water vapor transport to this region, which contributes to a diminished wet bias over South China. In contrast, three out of the five models in B_group overestimate the meridional wind speed, causing a wet bias over the whole of South China. Thus, both the analyses of the ensemble mean and individual models show that the better simulation skill for precipitation and extreme precipitation over South China possessed by A_group may be attributable to the more realistic meridional wind during its rainy season.

Further, to detect the causes for the model bias of extreme precipitation over Indochina, the observed and simulated May-October vertically integrated water vapor flux and water vapor flux divergence from the surface to $100 \mathrm{hPa}$ by the two groups, as well as their differences, are illustrated in Fig. 12. In the observation (Fig. 12a), there is abundant water vapor convergence over the whole of Indochina. Overestimated zonal water vapor transport from the northern Indian Ocean to 
(a) JRA55

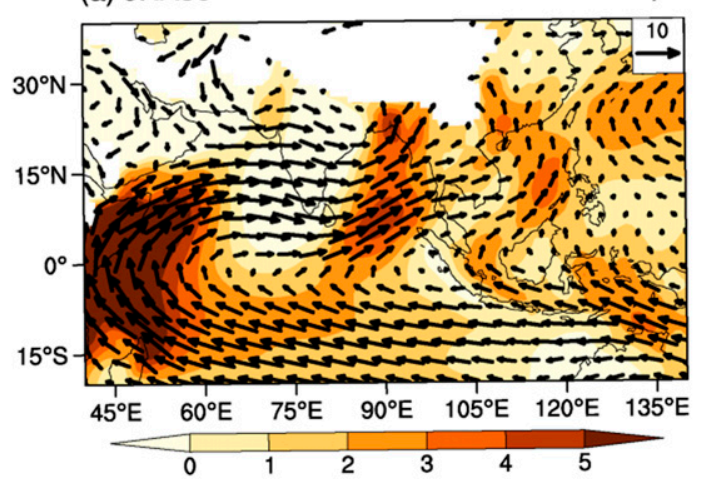

(b) A _ group - JRA55

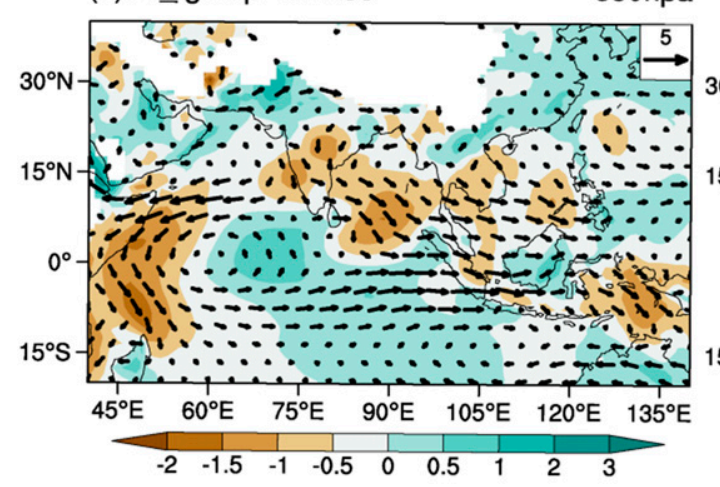

(c) B_group - JRA55

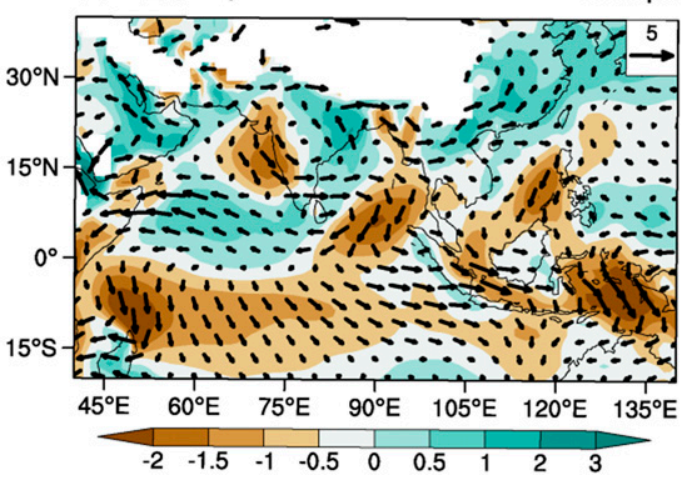

FIG. 11. Spatial distributions of the April-September-mean meridional wind speed (shading; $\mathrm{m} \mathrm{s}^{-1}$ ) and wind (vectors; $\mathrm{m} \mathrm{s}^{-1}$ ) at $850 \mathrm{hPa}$ from (a) JRA55 and (b),(c) the differences between JRA55 and two model ensembles.

Indochina is apparent in both groups (Figs. 12b,c). This more abundant water vapor convergence in Indochina simulated by the model ensembles of A_group and B_group leads to the in situ wet bias apparent in Figs. 8b, 8c, $8 \mathrm{e}$, and $8 \mathrm{f}$. Although the precipitation and extreme precipitation simulated by both groups over Indochina are relatively large, the wet bias of A_group is relatively smaller and closer to the observed. This is related to the weaker water vapor convergence in Indochina simulated by A_group compared with B_group (Fig. 12d). In terms of the analyses of water vapor transport and convergence for each model in the two groups (see Fig. S12), the model bias of water vapor convergence in Indochina of A_group is generally smaller than that of B_group. In addition, both the spatial variation and interannual variability of specific humidity and vertical velocity in rainy season are simulated well by A_group, with larger pattern correlation coefficients and smaller centered normalized RMS differences and IVS skill scores, compared with B_group (Table S9). Thus, the more accurate simulation by the A_group models of water vapor convergence, moisture conditions, and vertical motion leads to more realistic precipitation and extreme precipitation in Indochina.

Although many previous studies (e.g., Diffenbaugh et al. 2005; Hack et al. 2006; Walker and Diffenbaugh 2009) have indicated that models with higher horizontal resolutions can better capture fine-scale climate processes (e.g., Asian monsoon variability), the model horizontal resolution does not seem to be the main factor determining the model skill in simulating precipitation and extreme precipitation in the INCSC region, as not all the models in A_group are high-resolution models. Therefore, there is still some room to improve the model representation of the key physical processes connected with precipitation and extreme precipitation (Raghavan et al. 2017).

\section{Conclusions and discussion}

In this study, we quantitatively evaluated and ranked CMIP6 models based on their performance in simulating the spatial pattern and temporal variability of extreme precipitation indices in South China and Indochina for the period 1958-2014. Based on the overall model rankings, we selected the most and least skillful models for South China and Indochina separately. The possible causes of the model biases among the two ensembles (A_group and B_group) were also investigated. The main findings of this study can be summarized as follows:

1) Most of the CMIP6 models have difficulty in reproducing the observed spatial patterns of extreme precipitation indices in South China and Indochina, given the small spatial correlation coefficients. Only a few models are able to successfully reproduce both the spatial pattern and the interannual variability for the INCSC region. The wet bias 

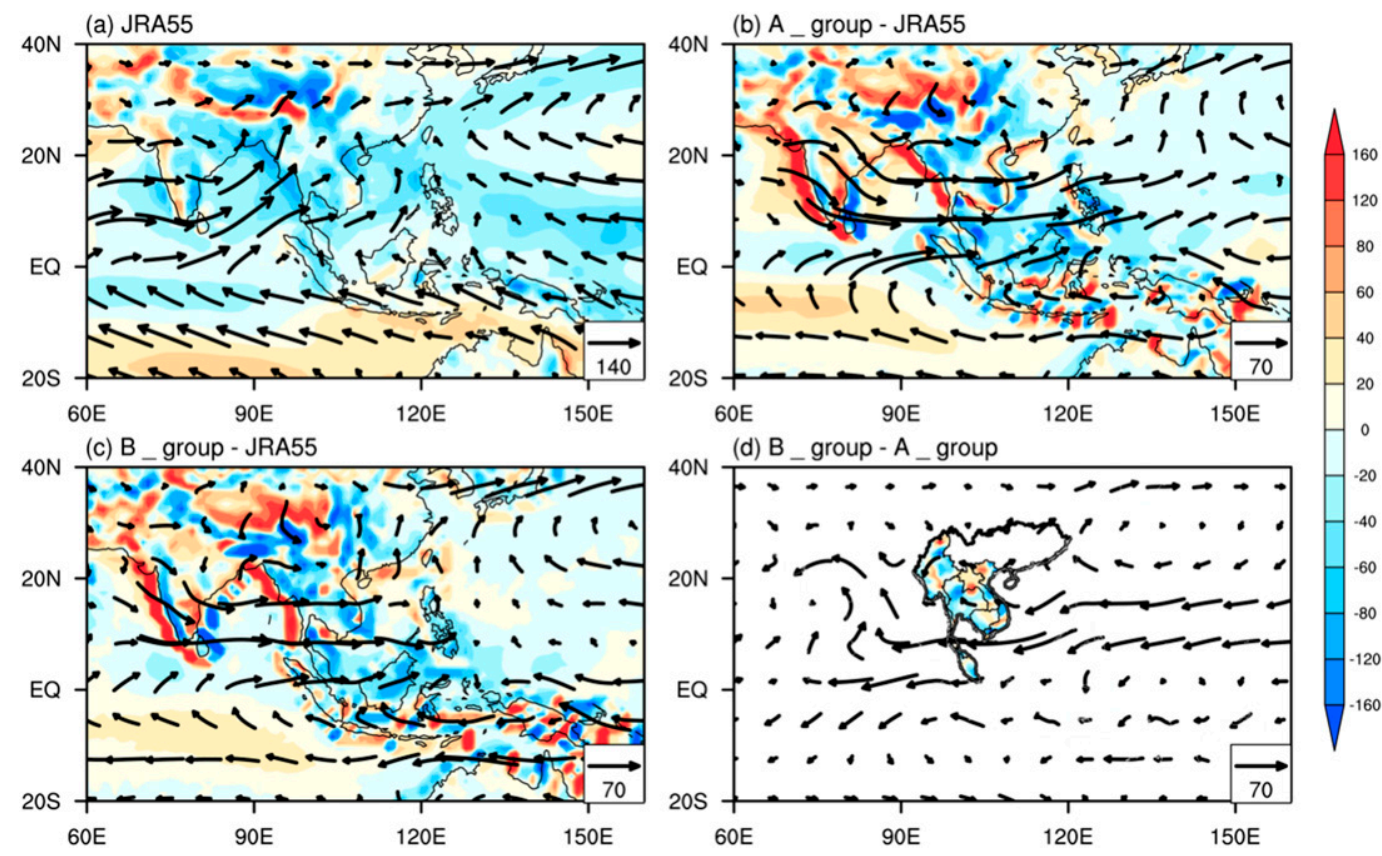

FIG. 12. The May-October-mean vertically integrated water vapor flux (vectors; $\mathrm{kg} \mathrm{m}^{-1} \mathrm{~s}^{-1}$ ) and water vapor flux divergence (shading; $10^{-6} \mathrm{~kg} \mathrm{~m}^{-2} \mathrm{~s}^{-1}$ ) from the surface to $100 \mathrm{hPa}$ in (a) JRA-55, (b),(c) the differences between two model ensembles and JRA-55, and (d) the difference between A_group and B_group.

over Indochina that exists in CMIP5 models still exists in CMIP6 models.

2) For South China, the spatial pattern of SDII is simulated well by most of the CMIP6 models. For Indochina, the spatial patterns of the extreme precipitation indices are poorly simulated, except CDD. With regards to interannual variability, all of the indices are relatively well simulated by the majority of CMIP6 models in South China, whereas the models possess limited simulation skill for the interannual variability of R95p and SDII in Indochina. Generally speaking, the interannual variability of extreme precipitation indices are relatively better simulated for South China than for Indochina. Most of the CMIP6 models perform better in South China compared with Indochina when taking both the simulations of spatial pattern and interannual variability into consideration.

3) For both South China and Indochina, the ability of each model in simulating the spatial pattern of extreme precipitation indices does not agree with the capacity for simulating the interannual variability. Through comprehensive consideration of the model capacities for simulating the spatial pattern and interannual variability of extreme precipitation, four models (CAMS-CSM1.0, EC-EARTH3, EC-EARTH3-Veg, and NorESM2-MM) were selected as the A_group ensemble for South China. The seven leading models for Indochina were ACCESS-CM2, EC-EARTH3, EC-EARTH3-Veg, HadGEM3-GC31-LL, MRI-ESM2.0, NorESM2-MM, and UKESM1.0-LL. EC-EARTH3, ECEARTH3-Veg, and NorESM2-MM were included in A_group for the two subregions, indicating that these three models possess certain skills in reproducing the spatiotemporal variation of extreme precipitation indices in the INCSC region.
4) The simulations of precipitation and extreme precipitation in South China by A_group are closer to the observations than those by B_group, which may be due to the more realistic representation of the meridional wind component over South China by the A_group models during its rainy season (April-September). For Indochina, well-simulated water vapor convergence, moisture conditions, and vertical motion by A_group contribute to the reduced model bias in simulating precipitation and extreme precipitation from May to October.

Given that the precipitation and extreme precipitation are drastically different between dry season and wet season in INCSC region (Waliser and Gautier 1993; Chang et al. 2005), we also evaluated model simulation skills on rainy season basis (Figs. S7-S10; Tables S5-S8) to conduct a comparison with the results on annual basis presented above. The periods AprilSeptember and May-October were chosen as the rainy season for South China and Indochina, respectively. In general, most skillful models are quite consistent whether the evaluation was done on annual basis or rainy season basis, taking both spatial variation and temporal variation into account (Fig. S10 vs Fig. 6). The best-performing models for South China always include EC-EARTH3, EC-EARTH3-Veg, and NorESM2MM, while ACCESS-CM2, EC-EARTH3, EC-EARTH3-Veg, HadGEM3-GC31-LL, NorESM2-MM, and UKESM1.0-LL are always the most skillful model for Indochina. In other words, EC-EARTH3, EC-EARTH3-Veg, and NorESM2-MM can reproduce the spatial pattern and the interannual variability well for the whole INCSC region whether they are evaluated on annual or rainy season basis. 
In this study, a common $1^{\circ} \times 1^{\circ}$ resolution for the CMIP6 models and observations was utilized for comparison; however, the gridded observational data may not be good enough to represent the extreme precipitation because INCSC is a region with complex topography. Therefore, the evaluation may to a certain extent have been affected by the shortcomings of the gridded observations. Furthermore, the INCSC region possesses large climate variability owing to the influence of complex air-sea interactions and teleconnections. Although many studies have demonstrated that increasing the horizontal resolution of models can improve the model capacity for simulating precipitation and extreme precipitation to a certain degree, the horizontal resolution does not seem to be the main factor determining the model simulation skill in the INCSC region. Therefore, there is still some room to improve the representation of the key physical processes connected with precipitation and extreme precipitation in the INCSC region. The performances of CMIP6 models in reproducing the monsoon circulation and El Niño-Southern Oscillation (ENSO) should be further evaluated, given they are tightly related with the spatiotemporal variation of precipitation and related extremes over the INCSC region. Meanwhile, it is relatively difficult for global models with coarse resolution to reproduce the effects of complex topography, perhaps resulting in poor simulations of the finer details of the rainfall distribution over the INCSC region (Chen et al. 2012; Giorgi 2019; Supari et al. 2020; Tangang et al. 2020). The application of regional climate models with high resolution in simulating extreme precipitation over the INCSC region is also worthy of further investigation. In addition, only the CMIP6 models were examined in this study. We intend to focus more on the comparisons between CMIP5 and CMIP6 models in our future work.

Acknowledgments. This work was jointly supported by the National Natural Science Foundation of China (41861144014, 41725018, 41875076, and 41606032).

\section{REFERENCES}

Alexander, L. V., and J. M. Arblaster, 2009: Assessing trends in observed and modelled climate extremes over Australia in relation to future projections. Int. J. Climatol., 29, 417-435, https://doi.org/10.1002/joc.1730.

$\longrightarrow$, and — 2017: Historical and projected trends in temperature and precipitation extremes in Australia in observations and CMIP5. Wea. Climate Extremes, 15, 34-56, https://doi.org/ 10.1016/j.wace.2017.02.001.

— mate extremes of temperature and precipitation. J. Geophys. Res., 111, D05109, https://doi.org/10.1029/2005JD006290.

Allan, R. P., B. J. Soden, V. O. John, W. Ingram, and P. Good, 2010: Current changes in tropical precipitation. Environ. Res. Lett., 5, 025205, https://doi.org/10.1088/1748-9326/5/ 2/025205.

Asian Development Bank, 2009: The Economics of Climate Change in Southeast Asia: A Regional Review. University of California Press, 226 pp.

Buckley, B. M., R. Fletcher, S.-Y. S. Wang, B. Zottoli, and C. Pottier, 2014: Monsoon extremes and society over the past millennium on mainland Southeast Asia. Quat. Sci. Rev., 95, 1-19, https://doi.org/10.1016/j.quascirev.2014.04.022.

Chang, C.-P., Z. Wang, J. McBride, and C.-H. Liu, 2005: Annual cycle of Southeast Asia-Maritime Continent rainfall and the asymmetric monsoon transition. J. Climate, 18, 287-301, https://doi.org/10.1175/jcli-3257.1.

Chen, L., Z. G. Ma, and X. G. Fan, 2012: A comparative study of two land surface schemes in WRF model over eastern China. J. Trop. Meteor., 18, 445-456.

Chen, T.-C., and J. Yoon, 2000: Interannual variation in Indochina summer monsoon rainfall: Possible mechanism. J. Climate, 13, 1979-1986, https://doi.org/10.1175/1520-0442(2000)013<1979: IVIISM $>2.0 . \mathrm{CO} ; 2$.

Chen, W. L., Z. Jiang, and L. Li, 2011: Probabilistic projections of climate change over China under the SRES A1B scenario using 28 AOGCMs. J. Climate, 24, 4741-4756, https://doi.org/ 10.1175/2011JCLI4102.1.

Chhin, R., H. H. Bui, and S. Yoden, 2017: Characterization of monthly precipitation over Indochina region to evaluate CMIP5 historical runs. Disaster Prevention Research Institute Bulletin, No. 60B, Kyoto University, Kyoto, Japan, 502-522, http://hdl.handle.net/2433/229375.

Chi, Y., J. He, and Z. Wu, 2005: Features analysis of the different precipitation periods in the pre-flood season in south China. J. Nanjing Inst. Meteor., 28, 163-171, https://doi.org/10.3969/ j.issn.1674-7097.2005.02.003.

Diffenbaugh, N. S., J. S. Pal, R. J. Trapp, and F. Giorgi, 2005: Finescale processes regulate the response of extreme events to global climate change. Proc. Natl. Acad. Sci. USA, 102, 15774 15778, https://doi.org/10.1073/pnas.0506042102.

Ebita, A., and Coauthors, 2011: The Japanese 55-year reanalysis "JRA-55": An interim report. SOLA, 7, 149-152, https:// doi.org/10.2151/sola.2011-038.

Eyring, V., S. Bony, G. A. Meehl, C. A. Senior, B. Stevens, R. J. Stouffer, and K. E. Taylor, 2016: Overview of the Coupled Model Intercomparison Project Phase 6 (CMIP6) experimental design and organization. Geosci. Model Dev., 9, 19371958, https://doi.org/10.5194/gmd-9-1937-2016.

— next level. Nat. Climate Change, 9, 102-110, https://doi.org/ 10.1038/s41558-018-0355-y.

Ge, F., X. Zhi, Z. A. Babar, W. Tang, and P. Chen, 2017: Interannual variability of summer monsoon precipitation over the Indochina Peninsula in association with ENSO. Theor. Appl. Climatol., 128, 523-531, https://doi.org/10.1007/s00704-015-1729-y.

— S. Zhu, H. Luo, X. Zhi, and H. Wang, 2021: Future changes in precipitation extremes over Southeast Asia: Insights from CMIP6 multi-model ensemble. Environ. Res. Lett., 16, 024013, https://doi.org/10.1088/1748-9326/abd7ad.

Giorgi, F., 2019: Thirty years of regional climate modeling: Where are we and where are we going next? J. Geophys. Res. Atmos., 124, 5696-5723, https://doi.org/10.1029/2018JD030094.

Hack, J. J., J. M. Caron, G. Danabasoglu, K. W. Oleson, C. Bitz, and J. Truesdale, 2006: CCSM-CAM3 climate simulation sensitivity to changes in horizontal resolution. J. Climate, $\mathbf{1 9}$, 2267-2289, https://doi.org/10.1175/JCLI3764.1.

Hui, P., J. Tang, S. Wang, X. Niu, P. Zong, and X. Dong, 2018: Climate change projections over China using regional climate models forced by two CMIP5 global models. Part II: Projections of future climate. Int. J. Climatol., 38, e78-e94, https://doi.org/ 10.1002/joc.5409.

IPCC, 2007: Climate Change 2007: The Physical Science Basis. Cambridge University Press, 996 pp. 
- 2013: Climate Change 2013: The Physical Science Basis. Cambridge University Press, 1535 pp., https://doi.org/10.1017/ CBO9781107415324.

Jiang, Z., W. Li, J. Xu, and L. Li, 2015: Extreme precipitation indices over China in CMIP5 models. Part I: Model evaluation. J. Climate, 28, 8603-8619, https://doi.org/10.1175/JCLI-D-150099.1.

Kanae, S., T. Oki, and K. Musiake, 2001: Impact of deforestation on regional precipitation over the Indochina Peninsula. J. Hydrometeor., 2, 51-70, https://doi.org/10.1175/15257541(2001)002<0051:IODORP $>2.0$. CO;2.

Kharin, V. V., F. W. Zwiers, X. Zhang, and M. Wehner, 2013: Changes in temperature and precipitation extremes in the CMIP5 ensemble. Climatic Change, 119, 345-357, https:// doi.org/10.1007/s10584-013-0705-8.

Kim, I.-W., J. Oh, S. Woo, and R. H. Kripalani, 2018: Evaluation of precipitation extremes over the Asian domain: Observation and modelling studies. Climate Dyn., 52, 1317-1342, https:// doi.org/10.1007/s00382-018-4193-4.

Kim, Y.-H., S.-K. Min, X. Zhang, J. Sillmann, and M. Sandstad, 2020: Evaluation of the CMIP6 multi-model ensemble for climate extreme indices. Wea. Climate Extremes, 29 100269, https://doi.org/10.1016/j.wace.2020.100269.

Krishnan, R., and Coauthors, 2015: Deciphering the desiccation trend of the South Asian monsoon hydroclimate in a warming world. Climate Dyn., 47, 1007-1027, https://doi.org/10.1007/ s00382-015-2886-5.

Li, J., Z. Liu, Z. Yao, and R. Wang, 2019: Comprehensive assessment of Coupled Model Intercomparison Project Phase 5 global climate models using observed temperature and precipitation over mainland Southeast Asia. Int. J. Climatol., 39, 4139-4153, https://doi.org/10.1002/joc.6064.

Mekong River Commission, 2010: State of the Basin Report 2010. MRC Secretariat, 123 pp., https://www.mrcmekong.org/assets/ Publications/basin-reports/MRC-SOB-report-2010full-report.pdf.

Misra, V., and S. DiNapoli, 2013: The variability of the Southeast Asian summer monsoon. Int. J. Climatol., 34, 893-901, https:// doi.org/10.1002/joc.3735.

Nguyen-Le, D., J. Matsumoto, and T. Ngo-Duc, 2015: Onset of the rainy seasons in the eastern Indochina Peninsula. J. Climate, 28, 5645-5666, https://doi.org/10.1175/JCLI-D-14-00373.1.

O'Gorman, P. A., 2012: Sensitivity of tropical precipitation extremes to climate change. Nat. Geosci., 5, 697-700, https:// doi.org/10.1038/ngeo1568.

Orlowsky, B., and S. I. Seneviratne, 2012: Global changes in extreme events: Regional and seasonal dimension. Climatic Change, 110, 669-696, https://doi.org/10.1007/s10584-0110122-9.

Ou, T., D. Chen, H. W. Linderholm, and J.-H. Jeong, 2013: Evaluation of global climate models in simulating extreme precipitation in China. Tellus, 65A, 19799, https://doi.org/ 10.3402/tellusa.v65i0.19799.

Pai, D. S., and L. Sridhar, 2015: Long term trends in the extreme rainfall events over India. High-Impact Weather Events over the SAARC Region, K. Ray et al., Eds., Springer, 229-240.

Potty, J., S. M. Oo, P. V. S. Raju, and U. C. Mohanty, 2012: Performance of nested WRF model in typhoon simulations over west Pacific and South China Sea. Nat. Hazards, 63, 14511470, https://doi.org/10.1007/s11069-011-0074-4.

Raghavan, S. V., J. Liu, N. S. Nguyen, M. T. Vu, and S.-Y. Liong, 2017: Assessment of CMIP5 historical simulations of rainfall over Southeast Asia. Theor. Appl. Climatol., 132, 989-1002, https://doi.org/10.1007/s00704-017-2111-z.
Rao, X., X. Lu, and W. Dong, 2019: Evaluation and projection of extreme precipitation over northern China in CMIP5 models. Atmosphere, 10, 691, https://doi.org/10.3390/atmos10110691.

Räsänen, T. A., V. Lindgren, J. H. A. Guillaume, B. M. Buckley, and M. Kummu, 2016: On the spatial and temporal variability of ENSO precipitation and drought teleconnection in mainland Southeast Asia. Climate Past, 12, 1889-1905, https:// doi.org/10.5194/cp-12-1889-2016.

Samuels, R., and Coauthors, 2017: Evaluation and projection of extreme precipitation indices in the eastern Mediterranean based on CMIP5 multi-model ensemble. Int. J. Climatol., 38, 2280-2297, https://doi.org/10.1002/joc.5334.

Sillmann, J., V. V. Kharin, X. Zhang, F. W. Zwiers, and D. Bronaugh, 2013: Climate extremes indices in the CMIP5 multimodel ensemble: Part 1. Model evaluation in the present climate. J. Geophys. Res. Atmos., 118, 1716-1733, https:// doi.org/10.1002/jgrd.50203.

Sun, Q., C. Miao, and Q. Duan, 2015: Extreme climate events and agricultural climate indices in China: CMIP5 model evaluation and projections. Int. J. Climatol., 36, 43-61, https://doi.org/ 10.1002/joc. 4328.

Supari, and Coauthors, 2020: Multi-model projections of precipitation extremes in Southeast Asia based on CORDEXSoutheast Asia simulations. Environ. Res., 184, 109350, https:// doi.org/10.1016/j.envres.2020.109350.

Tangang, F., and Coauthors, 2020: Projected future changes in rainfall in Southeast Asia based on CORDEX-SEA multimodel simulations. Climate Dyn., 55, 1247-1267, https:// doi.org/10.1007/s00382-020-05322-2.

Taylor, K. E., 2001: Summarizing multiple aspects of model performance in a single diagram. J. Geophys. Res., 106, 71837192, https://doi.org/10.1029/2000JD900719.

Toreti, A., and Coauthors, 2013: Projections of global changes in precipitation extremes from Coupled Model Intercomparison Project Phase 5 models. Geophys. Res. Lett., 40, 4887-4892, https://doi.org/10.1002/grl.50940.

Waliser, D. E., and C. Gautier, 1993: A satellite-derived climatology of the ITCZ. J. Climate, 6, 2162-2174, https://doi.org/ 10.1175/1520-0442(1993)006<2162:ASDCOT $>2.0$.CO;2.

Walker, M. D., and N. S. Diffenbaugh, 2009: Evaluation of highresolution simulations of daily-scale temperature and precipitation over the United States. Climate Dyn., 33, 1131-1147, https://doi.org/10.1007/s00382-009-0603-y.

Wang, Y., B. Zhou, D. Qin, J. Wu, R. Gao, and L. Song, 2017: Changes in mean and extreme temperature and precipitation over the arid region of northwestern China: Observation and projection. Adv. Atmos. Sci., 34, 289-305, https://doi.org/ 10.1007/s00376-016-6160-5.

Wu, L., R. Huang, H. He, Y. Shao, and Z. Wen, 2010: Synoptic characteristics of heavy rainfall events in pre-monsoon season in South China. Adv. Atmos. Sci., 27, 315-327, https://doi.org/ 10.1007/s00376-009-8219-z.

Yang, L., D. Wang, and S. Peng, 2008: Comparison between MM5 simulations and satellite measurements during Typhoon Chanchu (2006) in the South China Sea. Acta Oceanol. Sin., 31, 33-44, https://doi.org/10.1007/s13131-012-0190-3.

Yang, Y., R. Wu, and C. Wang, 2020: Individual and combined impacts of tropical Indo-Pacific SST anomalies on interannual variation of the Indochina Peninsular precipitation. J. Climate, 33, 1069-1088, https://doi.org/10.1175/JCLI-D19-0262.1.

Yatagai, A., K. Kamiguchi, O. Arakawa, A. Hamada, N. Yasutomi, and A. Kitoh, 2012: APHRODITE: Constructing a long-term 
daily gridded precipitation dataset for Asia based on a dense network of rain gauges. Bull. Amer. Meteor. Soc., 93, 14011415, https://doi.org/10.1175/BAMS-D-11-00122.1.

You, Q., Z. Jiang, D. Wang, N. Pepin, and S. Kang, 2017: Simulation of temperature extremes in the Tibetan Plateau from CMIP5 models and comparison with gridded observations. Climate Dyn., 51, 355-369, https://doi.org/10.1007/ s00382-017-3928-y.

Zhang, H., Fraedrich, K., Blender, R., and Zhu, X., 2013: Precipitation extremes in CMIP5 simulations on different time scales. J. Hydrometeor., 14, 923-928, https://doi.org/10.1175/ JHM-D-12-0181.1.
Zhang, X., and Coauthors, 2011: Indices for monitoring changes in extremes based on daily temperature and precipitation data. Wiley Interdiscip. Rev.: Climate Change, 2, 851-870, https:// doi.org/10.1002/wcc.147.

Zhong, L., L. Hua, Z. Ma, and Y. Yao, 2019: A quantitative study of moisture transport variation on the interdecadal variation of the summer precipitation in South China from 1979 to 2015. Climate Dyn., 53, 4743-4476, https://doi.org/10.1007/s00382-019-04822-0.

Zhu, H. H., Z. H. Jiang, J. Li, W. Li, C. X. Sun, and L. Li, 2020:Does CMIP6 inspire more confidence in simulating climate extremes over China? Adv. Atmos. Sci., 37, 1119-1132, https:// doi.org/10.1007/s00376-020-9289-1. 